\title{
2
}

\section{OBLIGACIONES HACIA GENERACIONES FUTURAS: EL CASO CONTRACTUAL}

Daniel Loewe*

\begin{abstract}
The article examines models of the diachronic extension of the moral community according to contractarian frameworks. It argues against the critics of the logical possibility of this kind of obligations and examines different contractarian theories based on self-interest and on impartiality. According to this examination the last kind of contractarianism provides the best arguments for these obligations. KEYWORDS - Moral community. Contractarianism. Obligations towards future generations. Self-interest. Non-identity-problem. Impartiality.
\end{abstract}

RESUMO - Neste texto, investiga-se a extensão diacrônica da comunidade moral no âmbito de teorias contratualistas. Para isso, examinam-se críticas à possibilidade lógica de sustentar obrigações em relação a gerações futuras e se abordam modelos argumentativos contratualistas de justificação dessas obrigações que se baseiam no interesse próprio e na imparcialidade. De acordo com essa pesquisa, a melhor defesa dessas obrigações se pode articular recorrendo a esse último tipo de contratualismo.

PALAVRAS-CHAVE - Comunidade moral. Contratualismo, Obrigações em relação a gerações futuras. Interesse próprio. Problema da não-identidade. Imparcialidade.

Que la moral refiere a un proceso de universalización es una premisa indiscutible. Pero esta universalización es frágil y sus fronteras sincrónicas y diacrónicas son difusas. Las controversias en torno a la extensión de la comunidad moral (a continuación CM) no son sólo especialmente virulentas, sino que en éstas nos encontramos comúnmente faltos de guías teóricas. Discusiones en torno al posible estatus moral de embriones y fetos, de animales no-humanos, de la naturaleza viviente no

* Profesor de Filosofía Política de la School of Government de la Universidad Adolfo Ibañéz, Santiago de Chile, miembro del Research Centre for Political Philosophy y del Interdepartmental Centre for Ethics in the Sciences and Humanities de la Universidad Tübingen. Este artículo es parte de un proyecto de investigación sobre Etica del Medioambiente financiado por la Fundación Thyssen.

\begin{tabular}{l|l|l|l|l|l} 
Veritas & Porto Alegre & v. 55 & n. 1 & jan./abr. 2010 & p. 21-66
\end{tabular}


sintiente, del medioambiente, pero también de las generaciones futuras (a continuación GGFF; en singular GF) y pasadas, son discusiones acerca de la estructura de la moralidad, o dicho de un modo menos controvertido, de la arquitectura de la teoría moral que se considera apropiada.

En este artículo me referiré a la inclusión de las GGFF dentro de la extensión diacrónica de la CM. Curiosamente, si atendemos a los debates en la teoría moral y política, podemos distinguir dos posiciones antagónicas que reclaman la evidencia de sus puntos de vista con respecto al estatus moral de las GGFF. Mientras que para los primeros es evidente que las GGFF pertenecen a la CM, para los segundos es evidente que esta inclusión es imposible. Común a las dos posiciones es la simplificación. En este artículo mostraré que es razonable afirmar que tenemos obligaciones morales hacia GGFF, pero que las estrategias argumentativas disponibles no son evidentes. Para esto procederé en cinco pasos. (1) En primer lugar explicitaré sucintamente lo que entiendo por CM. (2) En segundo lugar examinaré y rechazaré tres críticas usuales a la tesis que es posible tener obligaciones hacia GGFF. (3) En tercer lugar examinaré los límites y posibilidades de las estrategias contractuales para incluir a las GGFF en la CM. Para esto examinaré (3.1) teorías que se basan en el interés propio (Stemmer), y (3.2) teorías que refieren tanto a este interés como al valor de la imparcialidad (Rawls). (4) En cuarto lugar bosquejaré de un modo esquemático esta inclusión recurriendo a una teoría contractual que se basa en la imparcialidad. (5) Para terminar realizaré algunos comentarios finales.

\section{La comunidad moral}

Teorías (igualitarias) de moral establecen esferas en las que domina una igualdad fundamental. Esta igualdad no implica, prima facie, un trato igual, sino que una consideración igual de aquellos que valen como miembros de la CM. ${ }^{1}$ Pero aunque esta premisa formal puede ser

1 De este modo, teorías que establecen desigualdades en el trato no ponen esta premisa en cuestión, sino que interpretan las implicaciones de la consideración igual en modos diferentes. En mi opinión, el debate primeramente importante es - con las palabras de Sen (Sen 1980): “¿igualdad de qué?" y no: “¿por qué igualdad?”. Autores que ponen en cuestión el valor independiente de la igualdad, como Frankfurt (1997) y Raz (1986, capítulo 9), argumentan que no es la desigualdad entre los sujetos lo que motiva o torna necesario principios de moralidad política o de distribución, sino que la situación de privación en cuanto tal. Sin embargo, de este modo estas posiciones no pueden dejar de sostener la tesis de la primacia de la igualdad, aunque definida de un modo diferente - p. ej., en relación al respeto igual que se debe a cada cual al considerar sus necesidades. Para una tesis acerca de la primacía de la igualdad moral compare Tugendhat (1993, capítulo18; 2006); compare también Gosepath (2004). Un útil panorama sobre la discusión se encuentra en Krebs (2000). En este texto no me referiré a esta discusión. Traducciones al Español del autor (DL). 
aceptada, la determinación de la extensión de la CM es objeto de fuertes controversias.

De acuerdo al concepto formal utilizado en este texto, el estatus moral que va a la par con la membrecía a la CM establece una zona de protección que sitúa a otros bajo obligaciones morales directas. La extensión de la CM se determina en relación a todas aquellas entidades frente a las que se tiene obligaciones de este tipo. Este concepto de CM es fuerte: obligaciones directas son obligaciones hacia ciertas entidades, esto es, ellas son obligaciones debidas. Por cierto, es posible establecer obligaciones indirectas, esto es: obligaciones con respecto a ciertas entidades (y no sólo hacia ciertas entidades). Pero de acuerdo al mi uso conceptual, sólo aquellas entidades a las que les debemos obligaciones son miembros de la comunidad - con independencia de si el contenido de estas obligaciones exige que en nuestro accionar debamos considerar a otras entidades que no pertenecen a la comunidad en el sentido expuesto. De este modo, la pregunta acerca de la extensión de la CM se puede expresar del siguiente modo: ¿a quién - o a que entidades - le debemos algo desde una perspectiva moral?

Al plantearse la pregunta acerca de la extensión de la CM el primer paso es establecer cómo proceder. La estrategia usual de los filósofos frente a casos en los que falta un guía teórica es apelar a intuiciones. Pero con este procedimiento hay que ser cuidadosos. Primero: intuiciones son ciertamente importantes en el desarrollo de la reflexión moral. Ellas refieren a juicios que consideramos como verdaderos o correctos, sin saber porqué. Usualmente ellas expresan prejuicios cristalizados en un proceso histórico social. Esto no implica que las intuiciones no sean importantes en la reflexión moral. En cuanto resultados de un proceso histórico social ellas deben ser tomadas en serio. Pero intuiciones en cuanto tales no constituyen razones en la reflexión moral - es su examen crítico el que nos puede ayudar en la articulación de razones y argumentos morales. Segundo: aun si nos remitimos a un examen crítico de las intuiciones ampliamente aceptadas, y recurrimos, p. ej., a un tipo de equilibrio reflexivo que aspire a alcanzar una cierta coherencia entre nuestros juicios (intuitivos) bien meditados y los principios en que se basarían, como propone Rawls (1971; 1993), esta estrategia es poco productiva para determinar la extensión de la CM. Ciertamente es razonable proponer que, al menos en sociedades liberales democráticas, como aquellas en las que Rawls piensa que su liberalismo político encontraría un correlato en la cultura política de la sociedad, ciertas intuiciones encuentran amplia aceptación. P. ej., recurriendo a uno de los - en todo caso escasos - ejemplos dados por Rawls, que la esclavitud es injusta. Sin embargo, este modo de proceder no nos lleva suficientemente lejos en el caso 
de las preguntas relativas a los límites de la CM. A muchas de estas preguntas no encontramos respuestas ampliamente aceptadas, tampoco en aquellas sociedades que se caracterizan por una cultura política liberal y democrática. P. ej., si examinamos las intuiciones prevalentes con respecto al estatus moral de los animales no-humanos, encontramos posiciones que se caracterizan tanto por su completa inclusión como por su exclusión absoluta. ${ }^{2}$ La situación no es diferente cuando nos remitimos a intuiciones relativas al estatus moral de las GGFF.

En este texto examinaré las posibilidades que pueden ofrecer teorías contractuales para incluir a las GGFF en la CM. Este tipo de teorías expresa un entendimiento ampliamente compartido acerca de la arquitectura de la moral, de acuerdo a la cual ésta debe ser entendida como algo recíproco. ${ }^{3}$

\section{Derechos de generaciones futuras y obligaciones hacia éstas}

Las críticas a la idea que tenemos obligaciones morales hacia las GGFF o que las GGFF tienen derechos frente a nosotros, apuntan a diferentes momentos de la argumentación moral. A continuación examinaré críticas que afirman la imposibilidad lógica de estas obligaciones y derechos.

2 En un seminario sobre ética de los animales que dicte, una estudiante expresó su intuición que es correcto preocuparse más por su mascota, una serpiente en un terrario, que por una abuela desconocida que requiera su ayuda en forma urgente y por razones vitales. Y yo no creo que en este caso haya razones para poner en duda la honestidad de la intuición expresada.

3 Un entendimiento completamente diferente de la arquitectura de la moral la encontramos en las teorías utilitaristas. Ellas entienden la moral como algo unilateral (para una diferenciación similar, compare TUGENDHAT, 1997). En este texto no discutiré el utilitarismo. Tanto teorías contractualistas como teorías utilitaristas establecen normas morales genuinas, y deben ser, por tanto, diferenciadas de de otras fuentes de nuestras acciones hacia otros, como, p. ej., los ideales personales. Si aceptamos ideales personales en la definición de la CM, la inclusión de las GGFF no presenta ningún tipo de dificultades. El caso no es diferente de los ideales personales que, p. ej., refieren al trato del medioambiente. Lo que diferencia a las normas dependientes de un ideal personal de las normas morales genuinas, es que en la constitución de estas últimas hay una pretensión de universalidad. La aspiración de las normas morales de establecer un vínculo normativo universal pertenece a las normas morales como una característica semántica de éstas (compare MACKIE, 1981). Normas dependientes de un ideal personal pueden ser universalizadas desde una perspectiva lógica. Pero la pretensión de universalidad no es parte del carácter constitutivo de estas normas, como es el caso de las normas morales genuinas. El que de acuerdo a mi ideal personal tenga una obligación con respecto a las GGFF o al modo de tratar el medioambiente no implica ni la pretensión de que el cumplimiento de esta obligación sea exigible de cada cual, ni la aspiración de que esta obligación pueda ser justificable frente a cada cual. Pero en el caso de las normas morales genuinas la situación es diferente. 


\subsection{La condición de existencia}

Un argumento usual contra la posibilidad lógica de incluir a las GGFF en la CM refiere a su no-existencia actual. Comúnmente se lo presenta como un argumento irrebatible. De acuerdo a este argumento, una condición básica para sostener que se puede ser un receptor de las obligaciones morales de otros, o expresado con el lenguaje de los derechos, que se puede ser un portador de derechos morales, es la existencia. No tiene sentido decir que una entidad no-existente tiene derechos, o que tenemos obligaciones hacia ésta. Después de todo, ¿en qué podría consistir un derecho de una entidad no-existente o una obligación hacia ésta? Cualquier proceso de asignación de derechos o de obligaciones exige poder identificar al portador del derecho o receptor de la obligación. Pero si éste no existe, entonces no se pueden distribuir ni derechos ni obligaciones. Las GGFF no existen. Por lo tanto no tiene sentido afirmar que ellas puedan ser portadoras de derechos o receptoras de obligaciones.

Este argumento no es convincente. Primero: ciertamente tiene sentido afirmar que se puede tener una obligación aunque su receptor no exista. P. ej., podemos tener una obligación moral de ayuda a los necesitados $y$, por razones contingentes, vivir en una sociedad (o en un mundo - si extendemos el alcance de la obligación más allá de las fronteras políticas de nuestra sociedad, como una posición cosmopolita exige) en la que no hay entidades que puedan ser identificadas como necesitados. En este caso tenemos una obligación de ayudar a los necesitados aunque en forma contingente no los haya. Lo que esta obligación implica es que, en caso que haya un necesitado, debemos ayudarlo. La situación no es diferente en forma relevante a la de las GGFF. Si es el caso que en el futuro habrán otras generaciones, entonces podemos identificar a aquellos que van a existir como receptores de nuestra obligación o como portadores de derechos. $\mathrm{Si}$, por el contrario, los individuos pertenecientes a una generación se decidiesen en forma individual contra la procreación, porque, p. ej., adhieren a una religión sumamente ascética, aunque sería quizás lamentable, no habría nada moralmente reprochable en el fin de la especie humana (compare FEINBERG, 1980). De este modo, si tenemos obligaciones hacia las GGFF o si éstas tienen derechos, esto no implica ni nuestra obligación de hacerlas existir ni su derecho a existir.

Esto se suele denominar derechos condicionales. Evidentemente, la idea de un derecho condicional implica que debemos suponer que habrá o que puede haber GGFF. Si fuese posible establecer con certeza absoluta que, p. ej., la tierra se tornará inhabitable para cualquier forma de vida a partir del año 2050 (aunque evidentemente la posibilidad empírica para realizar este tipo de pronósticos es dudosa), no tendría sentido proponer 
que tenemos una obligación con respecto a GGFF que se extiendan más allá de esta fecha. Pero en la práctica, los filósofos que consideran problemática la inclusión de las GGFF en la CM no ponen en cuestión la continuidad de la especie humana en el futuro inmediato y mediato. Por lo demás, la dificultad extrema implícita en la realización de pronósticos certeros acerca del punto temporal en el cual la vida (humana o animal) será absolutamente imposible, permite articular argumentos para no descartar la posibilidad de que efectivamente vaya a haber GGFF. Por lo tanto, no habría ninguna razón para sostener que obligaciones hacia GGFF sean lógicamente imposibles porque éstas no existen en forma actual.

Segundo: se puede argumentar que una diferencia relevante para la argumentación moral entre ambos casos es que la obligación de ayudar a los necesitados se torna efectiva - es decir la exigencia de acción implicada en esta obligación se torna obligante - en el momento en que encontramos a un necesitado. Antes de encontrarlo, la obligación no exigiría nada de nosotros. A diferencia de esto, una obligación hacia GGFF exigiría de nosotros que actuásemos de una cierta manera en el presente. Por cierto, la actualidad de las exigencias en el caso de las obligaciones hacia GGFF es lo que en las discusiones públicas y políticas torna tan difícil su reconocimiento. Su reconocimiento implicaría en muchos casos una renuncia actual (p. ej., al uso de ciertos recursos naturales o al gasto de recursos invertibles). Sin embargo, este argumento está mal presentado en varios modos. Primero: si lo que se pretende afirmar es que, en tanto no encontremos a un necesitado la obligación en cuestión no tiene implicaciones en nuestras vidas, el argumento es falso. El temor de encontrar a un necesitado, y de lo que el cumplimiento de la obligación exigiría en este caso, pueden tener grandes implicaciones en nuestra vida - sobre todo si la obligación moral es exigente. Segundo y más importante: la obligación de ayudar a los necesitados puede implicar una obligación actual, aun cuando, como un asunto contingente, éstos no existiesen en el presente. P. ej., la obligación con respecto a los necesitados puede implicar participar en un fondo que, en el caso que surja un necesitado, se utilice para cumplir la obligación. En este caso el cumplimiento de la obligación frente a una entidad no-existente implica sacrificios en el presente. El caso no es diferente al de las GGFF.

Tercero: hasta ahora me he referido indistintamente tanto a nuestras obligaciones hacia las GGFF como a los derechos que éstas tendrían. Sin embargo, en un cierto sentido hay una discontinuidad real entre estas obligaciones y los derechos correspondientes. Como examinamos, la suposición razonable que van a seguir habiendo generaciones, implica que podemos identificar la clase receptora de nuestras obligaciones aunque esta clase no exista en el presente. Pero con el lenguaje de los derechos 
la situación es algo diferente. La idea de un derecho condicional nos dice que si es el caso que las GGFF existen, tendrán derechos frente a nosotros. Las GGFF sólo pueden ser portadoras de derechos bajo la condición de su existencia. La consecuencia lógica de esta afirmación es que ellas no tienen derechos ahora, sino que en el momento en que ellas existan.

Usualmente se trata de salvar esta brecha en la distribución de obligaciones y de derechos, en tanto se afirma que la existencia de las GGFF se puede entender en forma analógica a la futura existencia de un feto como entidad autónoma. Así, p. ej., de acuerdo a Feinberg: "en caso de una sucesión normal de los acontecimientos nuestra descendencia en cuanto colectivo existirá con la misma certeza con la cual un feto particular en el vientre de su madre en algún momento va a existir" (FEINBERG, 1980, 171). Sin embargo, esta analogía no salva la brecha. El que en caso de una sucesión normal de los acontecimientos un feto vaya a existir como entidad autónoma, no implica que a éste le correspondan actualmente los derechos que le corresponderán cuando sea una entidad autónoma. Y decir que "potencialmente" ya tiene estos derechos, tampoco ayuda. Argumentos de potencialidad no son sencillos, pero un derecho potencial es justamente eso: potencial, y yo no veo como se puede afirmar la actualidad de un derecho en base a su potencialidad. A esto se suma que, si los argumentos de potencialidad tienen algún tipo de plausibilidad - y yo no estoy afirmando que la tengan - ésta se basa en que la potencialidad tiene que ser entendida en relación a un proceso teleológico. Dicho de otro modo, el que bajo una sucesión normal de los acontecimientos una entidad $\mathrm{F}$ llegue a ser una entidad $\mathrm{H}$ debe ser entendido como el desarrollo de un proceso teleológico. Ciertamente esto distingue la "potencialidad" de un kilo de harina para transformarse en una torta de chocolate, cuando tienen lugar los acontecimientos M (la mezcla de éste con los otros ingredientes) y $\mathrm{H}$ (su cocimiento en el horno), de la potencialidad de un feto de llegar a ser un ser humano. Si un argumento de potencialidad tiene alguna plausibilidad, éste tiene que referir a este último caso, o a casos similares en que una cierta teleología es reconocible. $Y$ si bien es evidente que la humanidad tiende a perpetuarse a través de nuevas generaciones, como - al menos hasta ahora - muestra la historia de la humanidad, no es en forma alguna evidente que este proceso de perpetuación pueda ser entendido de un modo teleológico - a menos, claro, que se acepten premisas supra empíricas. El proceso de renovación generacional no es teleológico, y esto torna la analogía en una analogía imperfecta. Por lo tanto, este caso se distingue todavía más del caso en que, eventualmente, se podría proponer la existencia de un derecho en base a una potencialidad. Correspondientemente resulta la afirmación que las GGFF tienen derechos, aún más dudosa. 
Sin embargo, yo no pienso que la discontinuidad entre la distribución de obligaciones y la distribución de derechos constituya una buena razón para argumentar que es un sinsentido afirmar que las GGFF pueden tener derechos. La afirmación, que las GGFF tienen derechos aunque ellas no existan actualmente, y que estos derechos corresponden a obligaciones que - eventualmente - actualmente tenemos, expresa de un modo más nítido la idea de que éstas son obligaciones cuyo cumplimiento les debemos a ellas. De este modo, referirse a los derechos de las GGFF resalta un elemento constitutivo de estas obligaciones: la justificación moral de estas obligaciones - en caso que la hubiese - debe basarse en que estas generaciones son sujetos morales relevantes y, por tanto, sus intereses y necesidades deben ser considerados. ${ }^{4}$

\subsection{La indeterminación de los intereses}

Un segundo argumento que se articula contra la posibilidad de incluir a las GGFF en la CM se basa en la tesis de que la posesión de intereses (o, de un modo algo diferente, la posibilidad de identificar que algo es en interés de una entidad) es condición necesaria para ser portador de derechos o para ser receptor de las obligaciones de otros. Esta condición tiene una larga tradición en la filosofía del derecho. Si entendemos en forma tradicional derechos como protección de intereses, o como protección de la autonomía, en ambos casos suponemos que hay intereses fundamentales o transcendentales, que deben ser protegidos mediante reglas generales vinculantes.

Ciertamente la tesis del interés no es compartida de un modo general. P. ej., teorías que se basan en premisas biocéntricas y que gozan de amplia popularidad, como la Ética de Ehrfurcht vor dem Leben de Albert Schweitzer, no comparten esta premisa. ${ }^{5}$ En este texto no me referiré a

4 Por cierto, obligaciones debidas no son el único modo de vincular una obligación a las GGFF. Como mencioné en la nota número 3, obligaciones hacia las GGFF se pueden retrotraer, p. ej., a ideales personales sin implicar que éstas tengan derechos correspondientes. Y como veremos en la próxima sección, es posible fundar obligaciones en relación a las GGFF en los derechos de otros agentes actualmente existentes. Sin embargo, este modo de argumentar tiene límites estrechos.

5 De acuerdo a Schweitzer: "Yo soy vida, que quiere vivir, rodeado de vida, que quiere vivir". Así se constituiría el principio fundamental de la moral: "bueno es mantener y fomentar la vida; malo es aniquilarla e impedirla" (SCHWEITZER, 1974, 377). De acuerdo a esta doctrina, la vida en cuanto tal exigiría protección. Y ciertamente la validez de esta premisa no dependería de si las entidades vivientes tienen efectivamente un interés o algo puede ser identificado en su interés. Esto se torna patente en el rechazo de la condición de sintiencia como necesaria para poder proponer que una entidad puede tener derechos o que se pueden tener obligaciones hacia ésta. Sin algún tipo de sintiencia, esto es, sin la posibilidad de que para el agente un estado de cosas sea mejor o peor, no es posible asumir que hay un interés (consciente o inconsciente) que pueda ser protegido mediante derechos. 
este tipo de doctrinas éticas. En mi opinión, ellas pueden expresar un ideal personal. Pero su universalización como teoría moral no es posible. Ellas quedan en una zona difusa constituida por intuiciones religiosas o semireligiosas secularizadas que no se pueden justificar de un modo intersubjetivo. Y lo mismo vale en el caso de teorías morales que definen la CM de un modo aun más extensivo, como las teorías fisiocéntricas radicales, holistas o la así llamada deep ecology. ${ }^{6}$ Pero dejando de lado este tipo de teorías es posible afirmar que la tesis del interés es ampliamente aceptada. Esto se torna patente al observar que aquellos que cuestionan que animales no-humanos puedan ser portadores de derechos, usualmente afirman que éstos, aun cuando son sintientes y tienen estados mentales, no pueden tener intereses (compare, p. ej., FREY, 1979; en general DAVIDSON, 1985). ${ }^{7}$

Hay al menos tres tipos de críticas a la afirmación que podemos tener obligaciones hacia las GGFF o que éstas pueden ser portadoras de derechos que recurren a la tesis del interés.

1. La primera crítica se estructura en relación a la condición de existencia. De acuerdo a esta crítica, una condición necesaria para poder sostener que se tiene un interés, o que algo corresponde al interés de una entidad, es su existencia actual. GGFF no existen. Correspondientemente no pueden tener intereses y no hay nada que pueda ser considerado en

6 Ciertamente podemos considerar que determinados estados son más apropiados que otros para que una entidad pueda desarrollarse (llevar a cabo su teleología). P. ej., para el desarrollo de una planta es más apropiado que disponga de agua y de luz. Pero aquí hay que evitar confundir la claridad de la reflexión en razón de usos equívocos del lenguaje coloquial. En el caso señalado, la planta no tiene ningún interés, y tampoco podemos identificar un estado de cosas como en su interés (inconsciente o no reconocido). Quizás su florecimiento corresponde a mis intereses estéticos o medioambientales, pero ciertamente no a sus intereses. De hecho, la expresión "los intereses de la planta" sólo tiene un sentido analógico. Empleando la fórmula de Schweitzer, el que la planta quiere vivir porque se direcciona hacia su mantenimiento (como estructura biológica), no expresaría más que un uso analógico del lenguaje. La planta no quiere nada, y ciertamente tampoco vivir. En este sentido, resulta evidente que ella no tiene intereses que puedan ser protegidos. Para el defensor de este tipo de doctrina no son intereses los que están a la base de esta ética, sino que la premisa fundamental debe ser que - con las palabras de Schweitzer - "la vida en cuanto tal es sagrada".

7 De acuerdo a la argumentación de Frey, sólo se podría afirmar que algo puede ser en interés de un animal no-humano porque fomenta su bien. Pero en este sentido también se podría sostener que algo es en interés de un tractor (estar bien aceitado, etc.) porque fomenta su bien (lo que se considera como un buen tractor). Correspondientemente, si afirmamos que animales no-humanos pueden tener derechos, también tendríamos que afirmar que esto es válido en el caso de tractores u otros artefactos, lo que evidentemente sería un sinsentido (FREY, 1979). Esta argumentación se basa en malentendidos serios que no discutiré en este texto. 
su interés. Por lo tanto, habría una imposibilidad lógica para atribuirles derechos o considerarlas como receptoras de nuestras obligaciones. Sin embargo, esta crítica no es concluyente. Es posible rechazarla de un modo similar a como rechazamos la condición de la existencia: tal como las GGFF serán portadoras de derechos en la medida en que lleguen a existir, las GGFF tendrán intereses en la medida en que actualicen su existencia. Estos intereses son los que le otorgan substancia a nuestras obligaciones hacia las GGFF y los que, eventualmente, deben ser protegidos mediante derechos.

2. La segunda crítica no propone una imposibilidad lógica, sino que recurre a la falta de información disponible en la actualidad para individualizar los intereses de las GGFF. Si la razón para otorgar derechos refiere a la protección de intereses relevantes, en el caso de las GGFF surge el siguiente problema: aunque demos por sentada su existencia futura, no sabemos cuáles serán sus intereses. Sus condiciones de vida y concepciones del bien nos son desconocidas, y no sabemos si tendrán similitudes con las nuestras. De este modo, no podemos estar seguros de que la misma caracterización de nuestros y de sus intereses sea válida. De esta incompletitud de conocimientos es común deducir la conclusión que, si es el caso que tenemos alguna obligación hacia las GGFF, esta obligación debe ser que no debemos planificar en relación al futuro (compare, p. ej., GOLDING, 1981). Sin embargo, debido a una serie de razones, esta crítica no es concluyente:

Primero: el argumento de la incompletitud de conocimientos no articula una crítica a la idea de los derechos de la GGFF, como era la intención, sino que un argumento a favor de éstos. Aun cuando nada supiésemos con exactitud acerca de nuestra descendencia, derivar de esta falta de conocimientos que no tenemos obligaciones hacia éstas, es falso. La consecuencia que se obtiene es más bien, que tenemos al menos la obligación de no menoscabar las condiciones de vida de nuestros descendientes de un modo tan considerable, que para éstos sea imposible desarrollar una vida con dignidad. Por cierto, es evidente que cualquier decisión actual que refiera a nuestros descendientes limita - y en parte condiciona - sus propias decisiones. Esto resulta evidente cuando pensamos en la posibilidad de anclar sus derechos en nuestras leyes. Pero ésta no es una crítica a la posibilidad de, p. ej., legislar tomando en consideración a las GGFF. Si se considera que debido a la incompletitud de conocimientos hay que abstenerse de considerar a las GGFF y correspondientemente que no se les deben atribuir derechos o que no se debe asignar obligaciones hacia éstas, no se atiende suficientemente al hecho que, abstenerse de decidir algo que pudiese limitar las decisiones 
de nuestros descendientes, no se diferencia de un modo relevante de una decisión: "abstención" no es la respuesta que queda cuando rechazamos la posibilidad de interferir con las GGFF. Por el contrario, ella es también un modo de comportamiento moral hacia las GGFF - incluso uno, que deja a la descendencia a merced de la arbitrariedad.

Segundo: si bien es evidente que no disponemos de completitud de conocimientos para individualizar los intereses de las GGFF, esto no implica que no podamos identificar algunos de estos intereses. Universalización (ponerse en la posición de otro, p. ej., de los seres humanos del futuro) pertenece al núcleo de la moral. Y ciertos datos empíricos que juegan un papel importante en este proceso de universalización muestran una cierta constancia, incluso entre culturas y generaciones. El interés en no ser sujeto de violencia arbitraria, en disponer de ciertos recursos, etc. pueden ser generalizados y aplicados a las GGFF. Los contenidos de los intereses de las GGFF (de los que sabemos poco) se pueden determinar en razón de características centrales de los individuos actuales. Y si los intereses de las GGFF son expresados de un modo suficientemente general, la crítica de la incompletitud pierde toda base. A esto se suma que nuestro accionar actual es ya una estrategia de forjamiento de los intereses de las GGFF, al menos de aquellas que no están tan lejos de nuestra existencia. Políticas educacionales, el sistema de normas morales y legales que favorecemos (que están inmanentemente dirigidas al futuro de varios modos - compare, p. ej., BIRNBACHER, 1988, 92 y siguientes), son modos en que se condicionan ciertos intereses de las GGFF. Los intentos de cualquier sociedad de perpetuarse en el futuro, en tanto se traspasan elementos culturales entre generaciones, son modos de condicionar los intereses de las próximas generaciones, aunque, evidentemente, sin ninguna garantía de éxito.

3. La tercera crítica se basa en que, de acuerdo a ciertas concepciones del derecho, sólo se pueden atribuir derechos a sujetos singulares que pueden ser individualizados. Pero "generaciones" no son sujetos singulares, sino que colectivos indeterminados. Con referencia a los intereses (o a la capacidad de actuar - depende de que concepción de derechos favorezcamos) esta crítica afirma que son los individuos singulares los que pueden tener intereses que pueden ser protegidos por derechos, pero no los colectivos indeterminados. Sin embargo, esta crítica no es conclusiva: no es problemático otorgar derechos a determinados colectivos. Derechos de colectivos pueden referir a los derechos de una persona jurídica, como, p. ej., corporaciones del derecho privado (como clubs) y público, o a instituciones públicas (como comunas). Ciertamente las GGFF no son individualizables del modo en que lo es, p. ej., una 
corporación, en la cual, tanto las reglas que organizan la institución y las cadenas de tomas de decisiones, como sus miembros pueden ser individualizados. Pero si esta diferencia es relevante, lo es sólo desde la perspectiva de una teoría de la responsabilidad colectiva que pretende conectar (de un modo reduccionista o no) las responsabilidades colectivas a la responsabilidad de los miembros particulares (como, p. ej., las teorías de responsabilidad colectiva articuladas por FRENCH, 1984 y MAY, 1989). Dado que su no-existencia torna imposible considerar a las GGFF como actores morales, y en este sentido, sujetas a consideraciones de responsabilidad, esta diferencia no es relevante. En modo similar al caso del derecho corporativo, se pueden retrotraer los intereses de las GGFF a los intereses de sus miembros. Y estos intereses, como vimos, se pueden determinar en razón de características centrales de los individuos actualmente existentes.

\subsection{Reclamar los propios derechos}

Una tercera crítica a la posibilidad de otorgar derechos morales a las GGFF se basa en que, de acuerdo a una opinión común, una condición necesaria para este otorgamiento es que se debe estar en la posición de poder exigir el cumplimiento de la obligación moral correspondiente. De acuerdo a esta crítica, ya que la no-existencia de las GGFF torna imposible que puedan reclamar sus derechos y exigir el cumplimiento de las obligaciones morales correspondientes, por razones inmanentes a la lógica de los derechos, GGFF no podrían tener derechos. Sin embargo, esta crítica se basa en premisas falsas:

Primero: la posesión de un derecho no implica que se deba estar en la posición de poder reclamarlo. Esto queda en claro si examinamos, p. ej., la ya clásica concepción de derecho legal acuñada por Hohfeld. De acuerdo a esta concepción, un derecho es una ventaja otorgada a una persona legal mediante reglas legales. Las ventajas de una persona traen consigo desventajas para otras. De este modo surge un sistema en el que cada elemento está en conexión con los otros elementos. En este sistema Hohfeld diferencia cuatro tipos de derechos. El primero es un derecho de libertad (liberty). De acuerdo al análisis de Hohfeld este derecho tienen poco valor práctico, porque nadie está obligado a respetarlo (p. ej.: a mi derecho de libertad para caminar por el parque no le correspondería una obligación particular de otros para no interferir en mi caminata). ${ }^{8} \mathrm{El}$ segundo tipo de derecho corresponde a una demanda

8 En mi opinión, es difícil dar sentido a un derecho de libertad sin implicar en éste, al menos, una obligación de los otros para no interferir en mi libertad, pero esto no es relevante para la discusión actual. 
(claim). Una demanda exige el reconocimiento por parte de los otros: $\mathrm{mi}$ libertad puede estar limitada por demandas de los otros, si es el caso que tengo la obligación de actuar de un modo determinado frente una persona con una demanda (p.ej.: mi derecho de libertad para caminar está limitado por la demanda de otros para que no lo haga al interior de su propiedad, si es el caso que yo tengo la obligación de respetar esta demanda). El tercer tipo es el poder legal (power). Una persona puede utilizar sus poderes legales para limitar los poderes legales de otro (p. ej., cuando las personas entran en relaciones contractuales entre sí). El cuarto tipo de derecho es una inmunidad (immunity). Una inmunidad torna imposible que una persona pueda influir legalmente en otra. Una demanda estipula lo que no se debe hacer. Una inmunidad estipula lo que no se puede hacer. P. ej., ya que esclavitud está prohibida tanto a nivel nacional como internacional, legalmente no se puede esclavizar a ninguna persona. Personas tienen una inmunidad contra esclavitud.

Hay múltiples discusiones acerca de si ser portador de una demanda o de un poder legal debe implicar las capacidades necesarias para poder exigir la demanda o utilizar los poderes. Pero en el caso de la inmunidad la situación es diferente. El tener una inmunidad no exige, como condición, que se la pueda reclamar. Aunque aceptásemos la tesis de que la posesión de un derecho debe implicar la capacidad de poder exigirlo, esta tesis no se aplicara al caso de las inmunidades. De este modo, no es en forma alguna problemático que el portador de una inmunidad no disponga de la capacidad necesaria para exigirla. Siguiendo esta concepción es posible argumentar que, p. ej., animales no-humanos pueden tener al menos este último tipo de derechos. ${ }^{9} \mathrm{Y}$ de igual modo, no es problemático afirmar que las GGFF, aunque no disponen de las capacidades para exigir sus derechos, en tanto adquieren un estatus moral legalmente reconocido, pueden adquirir al menos inmunidades.

Segundo: la afirmación que una condición necesaria para poder ser portador de derechos (morales o legales) es que se debe disponer de la capacidad de poder reclamarlos, no sólo choca contra cualquier evidencia, sino que, por encima de esto, tiene consecuencias difíciles de aceptar. No todos los individuos a los que comúnmente se considera como portadores de derechos tienen las capacidades para reclamarlos. Un caso evidente son los niños. Niños son portadores de derechos aunque no disponen de

9 Steven Wise argumenta de este modo en la elaboración de su teoría legal, para afirmar que a los animales no-humanos con capacidades cognitivas similares a las de los seres humanos (otros primates) se les debería otorgar el estatus de portador de derechos legales al menos en relación a inmunidades - a las cuales los animales no-humanos "are more strongly entitled, and immunity rights are likely to be achieved first" (WISE, 2004). 
la capacidad para poder reclamarlos. Y la estrategia reduccionista, que aspira a reducir los derechos de éstos a los derechos de sus padres, no es plausible. Niños no son propiedad de los padres, y sus derechos los protegen también contra éstos. Por cierto sería posible articular algún argumento de potencialidad, como el arriba señalado, para justificar el hecho que los niños tienen actualmente derechos. Yo no consideraré este tipo de argumentos. En mi opinión, es evidente que los niños tienen derechos en cuanto tales y en cuanto seres humanos, independientemente del hecho si ellos llegarán a ser individuos que disponen de la capacidad requerida para poder reclamar sus derechos. Pero aunque aceptásemos argumentos de potencialidad y, por lo tanto, pusiésemos en cuestión que los derechos de los niños se oponen a la tesis que la posesión de un derecho exige la capacidad de poder reclamarlo, la plausibilidad de esta argumentación no se extiende a casos de individuos que no disponen de esta capacidad y que nunca dispondrán de ella, como es el caso, p. ej., de personas con ciertas deficiencias mentales severas. Sin embargo, es razonable postular que estos individuos tienen derechos, o al menos, que los pueden tener, con independencia del hecho que ellos no los pueden reclamar. Lo que todo esto indica es que el hecho contingente de no disponer de la capacidad para reclamar los propios derechos, no implica que no se pueda ser un portador de derechos. Esta conclusión es también válida en el caso de las GGFF, aunque lo que imposibilita que no se los pueda reclamar son razones lógicas (la posición temporal) y no contingentes.

Lo que es necesario, tanto en los casos arriba señalados como en el caso de las GGFF, es que si es el caso que no se dispone-por razones contingentes o lógicas - de la capacidad de poder reclamar los propios derechos, debe haber una tercera persona que en nombre del portador de derechos pueda o deba exigir el cumplimiento de la obligación moral correspondiente. Instituciones de custodia son corrientes en el caso de menores de edad, demencia, o enfermedades graves. Ellas también se pueden aplicar - y efectivamente se aplican - al caso de ciertos animales no-humanos. $\mathrm{Y}$ el caso de las GGFF no tiene porque ser considerado de otro modo.

En esta sección he examinado y rechazado tres críticas a la posibilidad de considerar a las GGFF como receptoras de nuestras obligaciones o como portadoras de derechos. De acuerdo a los análisis desarrollados, no hay dificultades conceptuales para considerar que podemos tener obligaciones hacia GGFF o que éstas pueden ser portadoras de derechos. Sin embargo, esto no implica que efectivamente tengamos obligaciones hacia éstas o que éstas tengan derechos. La posibilidad conceptual no implica una necesidad moral. Esta última depende de una teoría moral 
particular. El siguiente paso en el examen de los derechos de las GGFF es examinar los argumentos morales que se pueden articular a favor de éstos. De acuerdo a la metodología anunciada, examinaré cómo teorías que pueden inscribirse dentro de un horizonte contractualista amplio pueden incluir a las GGFF en la CM y así dar cuenta de las obligaciones hacia éstas o de sus derechos.

\section{Contractualismo diacrónico}

Teorías contractuales tienen una larga tradición en la filosofía política. En la actualidad ellas gozan de popularidad y amplia aceptación. Como es conocido, su actualidad se deja retrotraer a la tremenda influencia de la teoría de justicia de John Rawls en la filosofía política contemporánea (1971). Sin embargo, referirse al contractualismo como una teoría singular llama a equívocos. Hay una amplia gama de teorías contractuales. Éstas no sólo rivalizan entre sí, sino que en ocasiones se basan en premisas tan diferentes, que sólo se las puede clasificar como miembros de una familia extendida que comparten algunas características comunes.

Un elemento central dentro de la tradición contractual - pero que se cualifica de modos diferentes - es la reciprocidad. Los actores renuncian a algo en favor de las ventajas anticipadas con esta renuncia. P. ej., la renuncia de un sujeto a su libertad para ejercer violencia contra otros tiene lugar cuando los otros también renuncian a sus libertades para ejercer violencia en su contra. La ventaja asociada con renuncia a la propia libertad es la ventaja anticipada que se desprende de la renuncia de los otros a su libertad, y esta ventaja debe ser mayor que la pérdida de la propia libertad. O utilizando el lenguaje contractual: los individuos se deciden a abandonar el estado de naturaleza mediante el establecimiento de un contrato que avanza los intereses propios en tanto asegura ventajas mutuas.

De un modo similar al caso de los animales no-humanos, la reciprocidad de las tradiciones contractuales va ligada a problemas de difícil solución en el caso de la inclusión de las GGFF en la CM. ${ }^{10}$ La posición temporal diferenciada de los sujetos le sustrae a la teoría su fuerza justificativa: no es posible establecer relaciones de reciprocidad entre sujetos pertenecientes a generaciones distantes. ${ }^{11}$ ¿Por qué deberíamos, p. ej.,

10 En otro lugar he discutido los límites y posibilidades de las teorías contractuales para argumentar a favor de la inclusión de animales no-humanos en la CM constituida mediante el contrato (LOEWE, 2008).

11 Una historia ilustra esta imposibilidad: dos amigos, A y B, se encuentran casualmente. A le informa a $\mathrm{B}$ que $\mathrm{C}$ ha fallecido, y le pregunta si asistirá al entierro. B contesta: ¿por qué? ¿acaso va a asistir $\mathrm{C}$ a mi entierro? Esta es la situación en la que nos encontramos en relación a las GGFF con las que nuestra existencia no se traslapa. Esta historia se encuentra en Nozick (1974). 
renunciar al uso de recursos limitados de los que podríamos obtener ventajas, para así favorecer a los miembros de las GGFF? ¿Pueden ellos acaso renunciar a algo que nos pueda favorecer? Evidentemente no. Si esto es así, ¿cómo se podría justificar una obligación hacia GGFF dentro de la tradición contractual? Como examinaré, hay estrategias para incluir - al menos parcialmente-GGFF en la CM definida mediante el contrato. Sin embargo, estas estrategias son limitadas, y dependen del tipo de teoría contractual favorecida.

De un modo esquemático y corriente en la filosofía política podemos distinguir dos tipos de contractualismo que, como tipos ideales, se ubican en los extremos del espectro teórico contractual (compare BARRY, 1989, 1995; KYMLICKA, 1991). El primer tipo justifica obligaciones morales exclusivamente en relación al interés propio de los agentes. El segundo da por sentado en su justificación el valor moral de la imparcialidad. Ambas formas de contractualismo reconocen que los seres humanos, o al menos la mayoría de los seres humanos, son iguales. Pero ellas sostienen concepciones diferentes de esta igualdad. Hay pocas teorías contractuales puras. La mayoría combina elementos de ambas corrientes teóricas. De este modo, también encontramos teorías compuestas (compare NUSSBAUM, 2006, quien refiere a "teorías híbridas"). Posiblemente la teoría de Rawls es una teoría compuesta contractual que articula elementos de ambos tipos de tradiciones. A continuación examinaré la inclusión de las GGFF en la CM definida de acuerdo a (i) teorías contractuales que se basan en el interés propio, y a (ii) teorías contractuales compuestas.

\subsection{El interés propio y la inclusión de las generaciones futuras}

Teorías contractuales que proponen la promoción de los intereses propios mediante el afianzamiento de ventajas mutuas están directamente en la tradición de las teorías contractuales clásicas: ya que al asegurar los intereses mutuos el contrato promueve los intereses propios, los individuos están motivados a participar en un contrato y así abandonar el estado de naturaleza. ${ }^{12}$ La respuesta a la pregunta: "¿por qué debo asentir a la relación contractual?", es simultáneamente motivadora: porque corresponde a tu interés. Condición de esta forma de argumentación es que el contrato y el orden que éste legitima efectivamente promuevan los intereses propios. En este tipo de teorías "intereses" tienen un sentido

12 Dentro de los elementos teóricos contractuales en la teoría de derecho natural articulada por Locke tiene la benevolencia una gran importancia. Pero, a pesar de esto, los individuos son motivados porque mediante el contrato ellos pueden promover mejor sus intereses: "for their comfortable, safe, and peaceable living amongst another, in a secure Enjoyment of their properties, and a greater Security against any that are not of it" (LOCKE, 1960 (1679), capítulo 8, §95). 
reducido que refiere a fines privados y no a fines ajenos considerados mediante motivos altruistas. Negarse a asentir el contrato sería un signo de irracionalidad (entendida de un modo estrecho: se persigue un fin, pero se rechazan los medios que conducen a éste).

Este tipo de contractualismo - que en ocasiones también se denomina contractarianismo -, que encontramos expresado de un modo paradigmático, pero diferente, en Moral by Agreement (1986) de David Gauthier, o en Handeln zugunsten anderer (2000) de Peter Stemmer, expresa de un modo nítido las dificultades involucradas en la inclusión de las GGFF. La respuesta a la pregunta "¿quién pertenece a la CM?" tiene que ser articulada por referencia a todos aquellos en relación a los cuales tenemos buenas razones para querer establecer una relación contractual y que, al mismo tiempo, tengan buenas razones para querer establecer una relación contractual con nosotros. La pregunta es, por cierto, qué tipo de razones son consideradas como buenas razones, es decir, razones atingentes para la argumentación moral. Y lo que es una razón atingente está determinado por la condición de racionalidad: la consecución de los propios intereses. P. ej., si tengo razones para suponer que soy suficientemente fuerte para imponer siempre mis intereses en el estado de naturaleza, sin arriesgar que su promoción se vea frustrada por las acciones singulares o concertadas de los otros, no tendría buenas razones para abandonar el estado de naturaleza mediante el establecimiento de una relación contractual. De este modo, la racionalidad de la relación contractual depende de la descripción del estado de naturaleza. Este es comúnmente caracterizado - con mayor o menor dramatismo - mediante escasez de bienes, mediante conflicto y, de un modo central para estas teorías, mediante una potencialidad de poder similar entre los individuos. ${ }^{13} \mathrm{La}$ igualdad entre los individuos que estas teorías proponen, es una similitud de poder, o expresado de un modo negativo, una similitud en la posibilidad de que los propios intereses sean frustrados por otros agentes. Esta igualdad torna posible la membrecía en la CM constituida mediante el contrato. Pero la potencialidad de poder de las GGFF, esto es, la posible amenaza que ellas constituyen para la consecución de nuestros intereses, es anulada por su posición temporal. De este modo, las GGFF estarían excluidas de la CM. A continuación examinaré en forma más detallada la posible inclusión de las GGFF en la $\mathrm{CM}$ constituida de acuerdo a este tipo de teorías. En este examen referiré a la teoría de Stemmer (2000; sobre todo capítulo 8).

13 Hobbes, p. ej., a quien usualmente se recurre como un representante clásico de esta forma de contractualismo, acentúa la igualdad de poder de la mayoría de los seres humanos, la cual se debería a su naturaleza. 


\subsubsection{La comunidad moral y la capacidad de poder}

De acuerdo a la teoría moral contractual articulada por Stemmer, la CM es el lugar de las acciones morales, y las acciones morales son definidas mediante la característica de ser-exigidas (el neologismo utilizado por Stemmer es: "Gefordertsein"). Esto quiere decir, que una acción moral es una acción que se debe realizar. Esta exigencia tiene validez con independencia del tipo de persona que se es, p. ej., que tipo de ideales personales sostenemos, y con independencia de los intereses particulares propios (compare STEMMER, 2000, 255). El deber moral y los derechos morales son artefactos que surgen de agreements (Inglés en original). Y estos agreements se basan en intereses que se puede suponer que cada uno tiene, y por lo tanto, de los cuales nadie se puede liberar.

Stemmer establece tres condiciones para poder ser parte de la CM. Estas condiciones se dejan retrotraer al concepto de deber moral que define a la comunidad. La primera es la condición de intereses: ya que los agreements que constituyen las obligaciones y derechos morales recurren a intereses que se puede suponer que todos comparten, una consecuencia lógica es que aquellos seres que no tienen intereses no pueden ser parte de la CM. La segunda es la condición de poder: sólo aquellos seres que disponen de posibilidades de acción, de las cuales los otros de un modo racional quieren protegerse, pueden ser miembros de la CM. Esta condición debe ser satisfecha por todos los miembros de la CM. De este modo, si A tiene posibilidades de acción de las que B tiene razones para querer protegerse, pero $B$ no tiene posibilidades de acción de las que A tenga razones para querer protegerse, no se puede establecer ninguna relación contractual entre $\mathrm{A}$ y $\mathrm{B}$, aunque $\mathrm{B}$ tiene razones para querer establecer esta relación con $\mathrm{A}$. Tanto A frente a $\mathrm{B}$, como B frente a A, deben disponer de las posibilidades de acción que tornen para el otro racional el querer establecer una relación contractual. De esta condición se desprende una característica central de la CM: la CM es un espacio de derechos y obligaciones recíprocas. Receptores morales (esto es: miembros de la CM que sufren la consecuencias de las acciones de los otros miembros), sólo pueden ser aquellos que son actores morales (esto es: aquellos que pueden actuar de acuerdo al carácter de las normas morales de ser obligantes). ${ }^{14}$ La tercera condición de membrecía en la CM

14 Este uso conceptual (moral patients y moral agents) es usual en las discusiones relativas a la ética de los animales. Teorías que defienden la membrecía de - al menos - ciertos animales (y también algunas teorías fisiocéntricas radicales que defienden la membrecía de la naturaleza no-sintiente) en la CM, ponen en cuestión la tesis que para ser miembro de la CM se deba ser agente moral, y proponen que ser un paciente moral es condición suficiente para poder ser considerado como un miembro de la CM (Compare, p. ej., REGAN, 1984). 
es la condición de racionalidad o autodeterminación: sólo seres que son capaces de autodeterminación racional pueden ser actores morales, esto es, capaces de hacer u omitir algo, porque es moralmente exigido.

Aunque estas tres son condiciones necesarias para la membrecía en la CM, y ninguna es por sí misma suficiente, a la condición de poder le corresponde un estatus especial. Esta condición tiene un carácter obligante, o dicho de otro modo, es aquella que le otorga contenido a la exigencia racional de querer estar en una relación contractual con los otros. Este carácter la diferencia de las otras dos condiciones. La posesión de intereses no es moralmente obligante, sino que simplemente una característica empírica, y no es posible (contra, p. ej., teorías utilitaristas) fundar obligaciones morales mediante referencia exclusiva a características empíricas. Dicho de otro modo: que un ser determinado tenga un interés particular no es una razón para no interferir en su consecución de este interés. Y la capacidad de algunos seres de poder actuar autónomamente, tampoco nos da una razón para establecer un agreement con ellos. Si sostenemos, como comúnmente en la tradición kantiana, que la racionalidad tiene un valor inherente que nos debe hacer respetar a todos aquellos seres que la posean (normalmente sólo seres humanos - pero ciertamente no todos los seres humanos -, así como otros seres racionales - p. ej., de acuerdo a Kant, ángeles), proponemos la existencia de una característica supra-empírica - esto es: es posible afirmar su presencia, pero no es posible verificarla. Pero afirmando una característica supra-empírica (en este caso, el valor inherente de la autonomía) no podemos convencer al escéptico moral que pregunta por qué debe aceptar la relación contractual con los otros. Apelar a la racionalidad como condición suficiente para ser miembro de la CM, sólo tiene sentido frente a todos aquellos que creen en la existencia de esta característica supra-empírica. ${ }^{15}$ De este modo, esta condición no es obligante para establecer una relación contractual. A diferencia de estos casos, si los argumentos válidos para establecer un contrato se relacionan con la promoción de los intereses propios racionales, disponemos de razones obligantes (a menos que seamos irracionales) para reconocer como miembros del contrato a todos aquellos que disponen de posibilidades de acción, de las cuales, de un modo racional, queremos protegernos, y no disponemos de ninguna razón para entender el conjunto de los socios

${ }^{15}$ De igual modo, apelar a la semejanza entre Dios y los seres humanos como argumento de membrecía a la CM sólo tiene sentido frente a todos aquellos que creen en la existencia del Dios correspondiente. 
del contrato de un modo más amplio. ${ }^{16}$ Por esta razón a la condición de poder le correspondería un estatus especial en esta triada.

De acuerdo a estas tres condiciones se determina la extensión de la CM. Animales no-humanos pueden satisfacer la condición de intereses. Algunos animales no-humanos (p.ej. un tigre) satisfacen también la condición de poder - es decir, tienen posibilidades de acción de las cuales racionalmente nos queremos proteger. Sin embargo, animales no-humanos no cumplen la condición de racionalidad. Ellos no disponen de la posibilidad de hacer u omitir una acción porque es moralmente exigida. De este modo, animales no-humanos no pueden ser miembros de la CM. O con las palabras de Stemmer: "entre los seres humanos y los animales se mantiene el estado de naturaleza" (STEMMER, 2000, 257). Esta imposibilidad también se aplica al caso de ciertos seres humanos que, en razón de impedimentos mentales serios, no son capaces de la condición de racionalidad, aunque ciertamente son capaces de acciones de las cuales tenemos razones para querernos proteger. Estos seres humanos no son actores morales, y nosotros los tratamos de un modo correspondiente en tanto, p. ej., no los consideramos responsables por sus acciones. Niños pequeños, de sólo algunos meses de vida, satisfacen la primera condición, pero no la tercera (por cierto habría que agregar que ellos tampoco cumplen la segunda). De acuerdo a Stemmer, seres que satisfacen la condición de racionalidad, aun cuando tengan grandes impedimentos, tienen normalmente la posibilidad de dañar a los otros en tanto ellos pueden movilizar a otros para este cometido -, y de este modo cumplirían también la segunda condición.

Sin embargo, aunque la satisfacción de la tercera condición parece ir comúnmente acompañada por el cumplimiento de las otras dos, hay, de acuerdo a Stemmer, un caso especial en que esto no es así: los miembros de las GGFF satisfacen la condición de autodeterminación (y ciertamente la condición de intereses), y también la condición de poder - sin embargo, ellos no satisfacen esta última condición frente a todos aquellos que actualmente viven. Cuando los miembros de las GGFF dispongan de la capacidad actual de dañar a otros, los miembros de las generaciones presentes estarán muertos, y por lo tanto no es posible que los miembros de las GGFF influyan, de un modo positivo o negativo, en los miembros de las generaciones presentes. Por lo tanto: "Los miembros de las GGFF

16 De este modo, de acuerdo a Stemmer, en un mundo en el cual una mitad de los seres vivos fuese racional, pero sin la posibilidad de influir en la otra mitad de seres vivos, mientras que la segunda mitad de seres vivos fuese racional, pero con la posibilidad de poder influir positiva o negativamente en las vidas de la primera mitad de seres vivos, sólo serían miembros de la CM los seres vivos de la segunda mitad (STEMMER, 2000, 60). 
pueden ciertamente ser miembros de una CM en el futuro, pero, ya que ellos no cumplen la condición de poder frente a aquellos que ahora viven, no pueden ser miembros de la CM, en la que aquellos que ahora viven organizan su vida en conjunto" (STEMMER, 2000, 258).

¿Significa esto que desde la perspectiva de una teoría contractual que se basa en el interés propio sólo se puede ser indiferente con respecto a la suerte de las generaciones futura? La respuesta a esta pregunta debe ser cualificada. Teorías contractuales como la de Stemmer pretenden identificar un núcleo reducido de normas morales básicas que pueden ser exigidas de cada cual en base a argumentos racionales, con independencia del tipo de persona que se sea. En este sentido la aspiración justificativa de la teoría es enorme. Este núcleo es lo que estas teorías denominan como moral. Pero estas teorías no niegan que las fuentes del modo como nos comportamos con respecto a los otros son variadas y no se pueden reducir a este núcleo moral contractual. Estas fuentes (p. ej., ideales personales o aspiraciones sociales) de nuestras acciones hacia los otros no están anuladas porque ellas no pueden ser exigidas de cada cual en el mismo sentido en que si lo pueden ser las normas morales que se derivan del contrato. De este modo, si la indiferencia mencionada implica que sólo se puede ser indiferente con respecto a las GGFF, la respuesta es no. Con referencia a, p. ej., ideales personales o aspiraciones sociales es ciertamente posible tomar en consideración a las GGFF al determinar nuestras acciones actuales. Pero esta no-indiferencia no es exigible de cada cual del modo en que sí lo es una obligación moral. Por otra parte, si la indiferencia mencionada es una indiferencia moral, que se sigue del hecho que no sería posible incluir a las GGFF en la CM, la respuesta correcta parecería ser que sí. Sin embargo, esta última respuesta no es obligante: el que no sea posible incluir a las GGFF en la CM, no implica necesariamente que dentro de un marco argumentativo contractual no dispongamos argumentos para considerarlas en nuestro accionar. Como mencioné al comienzo de este artículo, dentro de este marco es posible considerar a ciertos individuos, no porque son miembros de la CM, sino que de un modo indirecto que se retrotrae al modo cómo estos individuos se relacionan con los miembros de la CM, aunque ellos mismos no lo sean. A continuación examinaré esta estrategia en el caso de las GGFF.

\subsubsection{Obligaciones indirectas con respecto a las generaciones futuras}

Hasta ahora me he referido a GGFF como generaciones distantes. Es evidente que en un sentido temporal estricto la existencia de las GGFF no se puede traslapar con la existencia de otras generaciones (en el momento en que las GGFF existen, dejan de ser futuras). Sin embargo, usualmente referimos no sólo a generaciones distantes como GGFF, sino que también 
a generaciones cercanas cuya existencia, parcialmente, en ocasiones se traslapa con la nuestra. Este modo de referir a GGFF se retrotrae a que en el proceso de reproducción social comúnmente se considera la capacidad productiva de los individuos - y no exclusivamente su posición temporal - como criterio determinante de la existencia de una generación. De este modo, p. ej., se suele considerar a los niños pequeños como miembros de una GF, ya que todavía no son actores autónomos en el proceso de producción y reproducción social. "Generaciones" son abstracciones de un proceso continuo de reemplazamiento poblacional. En cualquier momento encontramos individuos que pertenecen a generaciones diferentes, cuyas existencias usualmente se traslapan durante una cierta extensión temporal, como las generaciones de los abuelos, los padres y los nietos. Así las GGFF, en el sentido de generaciones cercanas a la nuestra, pueden estar ya presentes de tal modo, que su consideración puede ser moralmente relevante. De acuerdo al modo como se articula la relación hacia estas GGFF cercanas, existentes o no, es posible bosquejar dos argumentos para considerarlas de un modo indirecto en nuestras decisiones actuales.

1. El primer argumento se basa en nuestro interés actual en que las GGFF puedan asumir las tareas necesarias para mantener en marcha a la sociedad con instituciones sociales, políticas y económicas estables y efectivas. Este no es un interés en los individuos que pertenecerán a las GGFF. Por el contrario, este es un interés que remite exclusivamente al interés propio: debido al proceso biológico de envejecimiento y a la perdida de capacidades que éste a menudo conlleva, la senectud, cada uno sabe que sus capacidades productivas y las capacidades productivas de los otros miembros de su generación no podrán mantener a la sociedad como una estructura que asegure ventajas durante todo el tiempo de su existencia, pero cada uno tiene interés en que la sociedad se mantenga como una estructura cooperativa que produzca ventajas de las cuales se pueda sacar provecho, aun cuando ya no se pueda participar en este proceso. En base a este interés propio, tendríamos una obligación indirecta con respecto a las GGFF, cuya existencia productiva se traslapará con la nuestra.

De acuerdo a Stemmer la CM se constituye por seres humanos adultos sanos (o al menos no tan dañados como para no disponer de la capacidad de autodeterminación, o de potencialidad de poder). De este modo, sería posible afirmar que la existencia sucesiva de miembros de la CM (adultos sanos) que mantengan a la sociedad como estructura cooperativa está asegurada sin remitir a las GGFF. Sin embargo, este argumento no puede sostener todo el peso del interés mencionado. De 
un modo casi trivial esto se debe a que, de acuerdo a esta teoría moral, niños pequeños - y probablemente no tan pequeños, si tomamos en serio la condición de poder - no son miembros de la CM. Pero nuestro interés sólo puede ser satisfecho si estos niños, que no son miembros de la CM, son formados de tal modo, que ellos puedan, en el futuro, mantener la empresa cooperativa en marcha. Stemmer ciertamente intenta justificar una cierta consideración de los niños en tanto afirma que, ya que en cuanto sociedad tenemos un interés en que éstos puedan mantener la empresa cooperativa en marcha, tenemos una obligación indirecta con respecto a aquellos niños que efectivamente pueden llegar a ser miembros cooperativos de las sociedad (lo que excluye del radio de esta obligación a todos aquellos niños que sufren de impedimentos tales, que con seguridad se puede sostener en razón de las 3 condiciones discutidas que nunca serán miembros de la CM). Esta obligación indirecta referiría a un interés que podemos razonablemente suponer en todos los miembros de la CM.

Problemático en esta argumentación es que, de acuerdo al interés mencionado no sólo tendríamos un interés en que aquellos niños que pueden llegar a ser miembros cooperativos de la sociedad sean formados, sino que también tendríamos un interés fundamental en que vaya a haber niños que efectivamente puedan ser formados del modo expuesto. Y si bien, como mencione más arriba, la mayoría de los filósofos que refiere a la posibilidad o imposibilidad de atribuir derechos a las GGFF no pone en cuestión que vaya a haber GGFF al menos en el futuro cercano, esta suposición razonable no es suficiente para asegurar la satisfacción del interés mencionado - sobre todo si hay formas para asegurarla de un modo más efectivo, como ciertamente los hay. De este modo, el interés propio mencionado nos debería llevar a establecer obligaciones para asegurar, primeramente, que vayan a haber GGFF que sean productivas durante todo el período de nuestra existencia. Dicho de otro modo, la primera obligación indirecta con respecto a las GGFF que se desprendería de este interés, es una obligación para crearlas. Esta obligación se tornaría efectiva, cuando los individuos dejen de reproducirse en razón de motivaciones privadas. Ya que las generaciones se suceden en el tiempo (los hijos serán padres, etc.), el interés propio mencionado llevaría a establecer una obligación indirecta que garantice (o que aseguraré tanto como sea posible) que se vayan generando nuevas generaciones y que éstas sean entrenadas de modo tal que lleguen a ser miembros productivos de la sociedad. ${ }^{17}$

17 El otro lado de la medalla de este tipo de argumentación, es que tendríamos también una obligación indirecta para evitar que la cantidad de miembros de las GGFF crezca por sobre un límite que imposibilite (p. ej., debido a razones medioambientales) que se generen las ventajas que se desea asegurar mediante el contrato. 
2. El segundo argumento recurre a instituciones sociales establecidas. Instituciones sociales de este tipo son la relación entre padres e hijos y entre abuelos y nietos. De acuerdo a esta argumentación, el interés de los padres o abuelos en sus hijos o nietos es suficientemente fuerte como para considerar transitivamente los intereses de los descendientes como sus intereses. De acuerdo a esta interpretación, los padres o abuelos hacen suyos los intereses de sus hijos o nietos, al menos en lo que refiere a intereses fundamentales como la continuidad de su existencia. En el caso de las GGFF tendríamos que extender este interés en el futuro: el interés de los padres o abuelos potenciales en los intereses de sus hijos o nietos futuros es suficientemente fuerte como para considerar que ellos hacen suyos los intereses de éstos. ${ }^{18}$ De este modo, sería posible establecer obligaciones en relación a futuros individuos que se basan en el interés actual de sus padres o abuelos potenciales.

Sin embargo, esta estrategia es sumamente limitada. Primero: no es evidente que podamos asumir la transitividad de los intereses entre individuos en razón del tipo de relación social o biológica. Si bien puede haber razones cognitivas (los padres conocen quizás mejor los intereses de sus hijos) y pragmáticas (referentes sobre todo a la coordinación social) para suponer que los padres representan los intereses de sus hijos - como comúnmente se asume a un nivel legal -, es evidente que los intereses de estos últimos no son reductibles a los intereses de los primeros. Hay padres que dañan intencionalmente a sus hijos, y muchos otros que lo hacen sin intensión. A un nivel legal la tesis de la irreductibilidad es ampliamente aceptada: la suposición que los padres son los mejores representantes de los intereses de sus hijos puede ser revisada y anulada cuando hay razones para suponer que este no es el caso.

Segundo: si afirmamos la reducción de los intereses fundamentales de los niños a los de sus padres, tenemos entonces que aceptar como en interés de éstos todo aquello que sus padres sostengan. Esto se tendría ciertamente que extender a posibilidades de acción como infanticidio, que han estado presentes en todas las épocas y en múltiples culturas.

18 Una tesis similar con respecto a la transitividad de intereses entre hijos y padres la encontramos en Locke, quien afirma que los padres son los mejores protectores de los intereses futuros de sus hijos. En The Second Treatise afirma: "Children, I confess are not born in this full state of Equality, though they are born to it. Their Parents have a sort of Rule and Jurisdiction over them when they come into the World, and for some time after, but 'tis but a temporary one [...] [W] hilst he is in an Estate, wherein he has not Understanding of this own to direct his Will, he is not to have any Will of his own to follow: He that understands for him, must will for him too...; but when he comes to the Estate that made his Father a Freeman, the Son is a Freeman too" (LOCKE, 1960, capítulos 55 und 58; 304-306). Como argumentaré a continuación, esta tesis no es plausible. 
Así se reducen los intereses referentes a la descendencia sobre los que los actores morales podrían lograr - en el sentido de Stemmer - un agreement para fundar obligaciones indirectas: ya que hay padres que consideran infanticidio como en el mejor interés de éstos (debido, p. ej., a malformaciones congénitas, a una gestación inapropiada, a la situación económica, a una constelación apropiada para alcanzar una vida mejor después del sacrificio, etc.), no sería posible sostener que en cada caso los niños tienen un interés en su existencia, y de este modo, que debe haber una obligación indirecta con respecto a los niños actuales y futuros (hijos y nietos) que implique que no se los debe dañar de un modo vital. El único interés fundamental que podríamos identificar como capaz de sostener un agreement, es que ningún agente debe poder identificar los intereses de otros individuos que los de sus hijos y actuar correspondientemente. Las obligaciones indirectas que se basarían en este acuerdo son sumamente reducidas: padres pueden hacer con sus hijos lo que consideren que corresponde a su interés, aunque así atenten contra su vida, pero no otros individuos, que tienen la obligación de abstenerse de dañar a los hijos de otros. Esto puede proteger a los niños del arbitrio de terceros, pero no del de sus padres. ${ }^{19}$

Las dos estrategias argumentativas examinadas son limitadas. Evidentemente, en tanto suponemos que cada generación tiene intereses similares a los mencionados, es posible argumentar que las obligaciones derivadas de estos argumentos se mantienen, en principio, indefinidamente en el futuro, y de este modo, que seguirán habiendo GGFF con respecto a las cuales las generaciones presentes del futuro seguirán teniendo obligaciones. Sin embargo, estos argumentos no nos dicen nada contra la posibilidad de acabar con la factibilidad de que pueda haber GGFF en un espacio temporal futuro que no se traslape con el período de nuestra existencia, o en un espacio temporal que se extienda más allá del periodo de vida de nuestros hijos o nietos. Y efectivamente podemos tomar decisiones que influencien de un modo vital, tanto la posibilidad de que vaya a haber generaciones más allá de las mencionadas, como la calidad de su vida. Pero de acuerdo a las posibilidades argumentativas que ofrece esta tradición contractual no podemos incluir ningún tipo de consideración hacia generaciones distantes. De este modo, en este marco teórico no encontramos argumentos contra la posibilidad de, p. ej.,

${ }_{19}$ De acuerdo a cómo entendamos el concepto de daño sería quizás posible extender el radio de las implicaciones de esta obligación. Con un concepto amplio se podría considerar como daño el destruir las capacidades medioambientales que posibiliten una vida de duración normal y con características consideradas como apropiadas. De este modo, eventualmente sería posible justificar una obligación indirecta con respecto a hijos y nietos para no destruir el medioambiente de tal modo que su vida se torne imposible o no llegue a ser suficientemente valiosa como para ser vivida. 
decidir ahora destruir la capacidad medioambiental de nuestro planeta o de saquear sus recursos naturales no renovables (y renovables, de tal modo que se tornen no renovables) y así tornarlo inhabitable o incapaz de sostener vidas humanas con una calidad mínima en un período que se extienda, digamos generosamente, a partir de ciento cincuenta años.

\subsection{Teorías compuestas: la teoría de justicia de Rawls}

La teoría de justicia de Rawls es una teoría de justicia social. Esto quiere decir, una teoría acerca de la justicia de las instituciones más importantes que organizan la estructura básica de una sociedad organizada estatalmente. En este sentido, la pretensión no es articular una fundamentación contractual de todas nuestras obligaciones morales, sino sólo de aquellas que se articulan mediante instituciones estatales. Por lo tanto, esta teoría utiliza un concepto de moral diferente al que examinamos en la teoría de Stemmer. En la teoría de Rawls, las obligaciones que se derivan del contrato no constituyen todo el espacio de la moralidad (definido por la característica de "ser-exigidas"), sino que hay otras fuentes de la moral que eventualmente pueden constituir obligaciones morales. La diferencia, es que éstas no son obligaciones de justicia social en el sentido expuesto.

Esta teoría contiene elementos de las dos tradiciones contractuales mencionadas. Por una parte, la sociedad es entendida como una empresa cooperativa que produce ventajas y cargas. De acuerdo al entendimiento de Rawls, en la sociedad está vigente lo que Hume denominó las "circunstancias de la justicia", esto es, diferentes concepciones del bien, escasez relativa de recursos y generosidad limitada de la naturaleza humana. De este modo, en razón de su interés en el desarrollo de sus planes de vida de acuerdo a las propias concepciones del bien, los individuos están motivados para establecer un contrato acerca de los principios de justicia que regulen la interacción social y distribuyan las ventajas que se obtengan de ésta. Por otra parte, Rawls recurre en su teoría a una intuición fundamental - con sus palabras: "uno de los puntos fijos de nuestros juicios meditados" (RAWLS, 1971, 104). De acuerdo a esta intuición, tanto nuestro punto de partida social y económico, como también nuestra dotación de talentos son "contingentes" y por lo tanto "moralmente arbitrarios" (arbitrary from a moral point of view). Ellos son resultado de la lotería natural, y por tanto nadie puede afirmar que los merece. Respondiendo a esta intuición Rawls elabora una nueva versión del estado de naturaleza, con un nivel de abstracción mayor al de las teorías contractuales clásicas, en el cual serían escogidos los principios de justicia. Este estado de naturaleza, que Rawls denomina "posición original" (a continuación: PO), corresponde a una posición de 
imparcialidad en la que estas diferencias "moralmente arbitrarias" son neutralizadas.

La PO está parcialmente caracterizada por el "velo de la ignorancia". Éste establece límites a los conocimientos disponibles al momento de escoger los principios de justicia: no disponemos de conocimientos particulares sobre nosotros mismos. No sabemos cuán privilegiados o desaventajados somos en comparación social. Tampoco sabemos cuáles son nuestras dotes innatas. Por encima de esto, sabemos que tenemos una concepción del bien, pero no sabemos cuál. En este contexto, los individuos deben escoger principios de justicia en razón de los cuales se organicen las instituciones políticas más importantes de la sociedad en la que ellos van a vivir. En la elección de los principios de justicia detrás del velo de la ignorancia los individuos no son impulsados por una motivación moral, sino que por su interés racional en poder perseguir sus planes de vida - sean éstos los que resulten ser - en la sociedad que se organice de acuerdo a los principios escogidos. De este modo, los individuos en la PO están interesados en sí mismos y son mutuamente desinteresados: ellos no están interesados en la suerte de otros individuos (es decir, son indiferentes: no escogen por motivos altruistas, y tampoco se dejan guiar por la envidia), sino que tratan de asegurar para sí, mediante la elección de principios, tantas ventajas como sea posible una vez fuera de la PO. Estas ventajas se expresan en la teoría de Rawls por referencia a los así denominados "bienes básicos" (primary goods). ${ }^{20}$ Bienes básicos son "cosas que se presume cada individuo razonable quiere" (1971, 62). Esto es así porque, de acuerdo a Rawls, los bienes básicos posibilitarían el desarrollo de nuestros planes de vida. Pero ya que en razón del velo de la ignorancia los individuos no saben quienes son en la sociedad (su concepción del bien, su fuerza física y talentos, así como su posición económica y social), no pueden preferir principios que los privilegien de un modo especial. Al escoger principios que avancen sus intereses, escogen simultáneamente principios que privilegien a cualquiera que se encuentre en su situación de elección. ${ }^{21}$

20 Este concepto ha sido definido de un modo exacto en la teoría. Bienes básicos son (i) libertades y derechos fundamentales, como nos son conocidos de los ordenes constitucionales, (ii) oportunidades en el acceso a cargos y posiciones sociales, (iii) recursos, definidos en relación a ingreso y riqueza, y (iv) las bases sociales del auto-respeto.

21 Esto no debe ser malentendido. La PO de Rawls no implica la participación de múltiples individuos en el establecimiento contractual de los principios. En sentido estricto, la PO articula un experimento mental: cualquier individuo se puede situar en la PO en tanto acepta estas restricciones cognitivas al guiar sus reflexiones morales para escoger principios de justicia. Pero la posibilidad de representar la PO por referencia a múltiples individuos tampoco está excluida: la presencia de múltiples individuos podría ser incluso ventajosa para superar problemas referentes a la racionalidad imperfecta de algunos individuos. 
De este modo, la PO representa una situación de imparcialidad, y las decisiones tomadas en ésta son justas (fair). ${ }^{22}$

La inclusión de las GGFF o la consideración de sus intereses en este contexto contractual no están exentas de controversia. Esta inclusión está sujeta a dificultades similares a las que encontramos en la versión contractual que se basa en el interés propio. Ya que Rawls entiende la sociedad como una empresa cooperativa, para ser socio en el contrato hay que disponer de un mínimo de capacidades productivas. Si algunos individuos estuviesen por debajo del mínimo estipulado de capacidades físicas y mentales, las ventajas anticipadas de la cooperación con ellos serían demasiado mínimas, y correspondientemente no habría ninguna razón para reconocerlos como socios en el contrato. Por lo mismo, y en concordancia con las teorías contractuales clásicas, Rawls afirma que los individuos son "rough equals", esto es, que los participantes en la PO disponen siempre por sobre un mínimo de capacidades físicas y mentales fuera de ésta, aunque no saben cuan dotados son por sobre este mínimo. Debido a las circunstancias de la justicia los "rough equals" están motivados en el establecimiento de un contrato que asegure ventajas mutuas. Problemático en el caso de la inclusión de las GGFF es que, si bien los individuos que pertenecerán a las GGFF serán miembros productivos de las sociedades futuras (en tanto posean al menos el mínimo estipulado de capacidades físicas y mentales), ellos no son "rough equals" en relación a los miembros de la generación actual. ${ }^{23}$ En sentido estricto, ellos no disponen de ninguna capacidad productiva que pudiese tornar ventajoso el establecimiento de un contrato. De este modo, no habría ninguna razón para considerar sus intereses al momento de escoger los principios de justicia que organicen las instituciones más importantes de la sociedad en la que viviremos y, por lo tanto, no habría ninguna posibilidad de justificar obligaciones de justicia hacia GGFF en forma contractual.

Sin embargo, Rawls sostiene que las GGFF tienen demandas justificadas hacia las generaciones presentes, y que éstas son compatibles con su modelo contractual. De hecho, estas demandas ocupan un lugar central en su teoría. Ellas determinar el "principio de ahorro justo" que

22 Rawls afirma que una decisión en la PO corresponde a una decisión benévola fuera de ésta.

${ }^{23}$ No es casual que la teoría de Rawls (en forma similar a la teoría de Gauthier) no tiene lugar para seres humanos con deficiencias mentales y físicas severas al nivel primario de la teoría, esto es: al nivel en el que se deciden los principios de justicia. El caso de los animales no-humanos es aun más claro: ya que los animales no son "rough equals", esto es: su capacidad de cooperación y de poder es mínima, no habría en la teoría ningún lugar para ellos como socios del contrato. Por consiguiente los animales no pueden ser sujetos de justicia. En otro lugar es discutido este punto (LOEWE, 2008). 
cualifica al segundo principio de justicia. A continuación examinaré las dos argumentaciones que Rawls articula para justificarlo.

\subsubsection{El principio de ahorro justo y las generaciones futuras}

Como es conocido, Rawls propone dos principios de justicia que serían escogidos en la PO. De acuerdo al primer principio: "Cada persona tiene un derecho igual al sistema total de libertades básicas iguales más extensivo que sea compatible con un sistema similar de libertad para todos". El segundo principio tiene dos partes y afirma que, las desigualdades sociales y económicas tienen que estar "vinculadas a posiciones y cargos abiertos a todos en condiciones de igualdad equitativa (fair) de oportunidades" (1971, 302), y tienen ser organizadas "para el mayor beneficio de los menos aventajados, consistente con el principio de ahorro justo". De este modo, este último principio, el así llamado Principio de la Diferencia, está limitado por el principio de ahorro justo que, según Rawls, los individuos escogerían en la PO. ${ }^{24}$

El principio de ahorro es una gran contribución a las teorías de justicia social. Sin embargo, no es evidente que los individuos lo escogerían. Este principio hace explotar los límites sincrónicos contractuales dentro de los cuales se pueden justificar los principios de justicia. Y Rawls está consciente de estos límites: si bien los individuos en la PO no saben a qué generación pertenecen, ellos saben que todos son contemporáneos. Esto tiene un buen sentido: sin esta contemporaneidad no parecen haber razones para establecer un contrato. P. ej., la elección del Principio de la Diferencia (que cualquier mejoramiento de los más favorecidos debe estar condicionado a un mejoramiento de los menos favorecidos) es racional cuando tenemos razones para suponer que nuestra existencia sincrónica en cuando desfavorecidos se traslapa con la de aquellos de los cuales podemos obtener ventajas. Pero este no es el caso cuando hay una brecha diacrónica entre generaciones: la razón para ahorrar de un modo que favorezca a GGFF, de las que no nos podemos beneficiar, tendría que ser el beneficio que esperamos obtener de las generaciones pasadas que ahorraron para nosotros. Pero es ciertamente absurdo suponer que podemos establecer un contrato con las generaciones pasadas.

1. La primera argumentación a favor del principio de ahorro se encuentra en $A$ Theory of Justice. En ésta Rawls rechaza la idea que los individuos en la PO tengan simplemente obligaciones hacia

${ }^{24}$ Más allá de afirmar que este principio depende del nivel y cuota de crecimiento, Rawls considera difícil su especificación (RAWLS, 1971, 287). En parte esto se debería a que sería poco lo que se podría afirmar acerca de las preferencias de las GGFF. 
sus descendientes inmediatos (RAWLS, 1971, 128). Aceptar esta idea implicaría una especificación excesiva de los individuos en la PO, lo que contradeciría la premisa básica que en la PO los individuos son mutuamente desinteresados. En vez de esto, Rawls asume una nueva premisa motivacional, que él denomina de "buena voluntad". De acuerdo a ésta, los individuos en la PO tienen que ser imaginados como representantes de líneas sanguíneas "as being so to speak deputies for a kind of overlasting moral agent or institution" (RAWLS, 1971, 128). En ocasiones Rawls refiere a éstos como "jefes de familia". De éstos no se espera que representen toda su línea sanguínea a perpetuidad, sino que los intereses de al menos las próximas dos generaciones. Así, Rawls afirma que es como si las diferentes generaciones estuviesen presentes en la PO. Como consecuencia de estas premisas motivacionales los individuos en la PO estarían de acuerdo con la inclusión de un principio de ahorro en la lista de principios de justicia.

Los problemas de esta argumentación son evidentes y han sido extensamente discutidos. Yo sólo mencionaré tres críticas. La primera crítica apunta al hecho que, aunque esta argumentación fuese conclusiva, ella no puede evitar la conclusión ya discutida en relación a la inclusión indirecta de las GGFF y sus intereses: si los "jefes de familia" representan los intereses de las próximas dos generaciones, no hay modo de evitar acciones que perjudiquen a las generaciones que eventualmente existirán después de éstas. Evidentemente, y esta es la pretensión detrás de esta argumentación, la consideración sucesiva de los intereses de las GGFF se podría extender al infinito como una cadena (sucesivamente los hijos serán padres que atenderán a los intereses de sus hijos, etc.) Pero lo que en este caso es posible en teoría puede ser frustrado en la práctica: bastaría con que una generación tomase decisiones que destruyesen la capacidad vital del planeta o se abstuviese de tomar decisiones que la mantuviesen más allá de estas dos generaciones (o tres, o cuatro, etc. el número es irrelevante), para que la cadena se rompiese. Por lo mismo, es evidente que apelando a este argumento no se puede afirmar que es como si todas las generaciones estuviesen presentes en la PO.

Segundo: no es claro por qué se puede asumir esta premisa de buena voluntad. Una posibilidad sería recurrir a una concepción de naturaleza humana. P. ej., según Kant: "Así lo trae la naturaleza humana consigo: incluso en vistas a la época más lejana en la que nuestra especie se puede extender, no ser indiferente cuando ésta se puede esperar con alguna seguridad" (KANT, AA VII, p. 27). Sin embargo, apelar a una cierta naturaleza humana no es convincente en este caso. A menos, claro, que asumamos que muchos seres humanos luchan contra su naturaleza, y con bastante éxito en el caso de la supuesta no-indiferencia con respecto a 
las GGFF. Otra posibilidad para asumir esta premisa de buena voluntad podría ser que se encuentra reflejada empíricamente en el modo en que los miembros de una generación comúnmente se preocupan por sus descendientes inmediatos. Pero el problema general de apelar a este tipo de motivación psicológica para justificar obligaciones hacia GGFF, es que éstas se extienden sólo hasta el punto al que esta motivación nos lleva. Y esta motivación es, como cualquier propiedad psicológica, no sólo contingente y por tanto diferente en diferentes individuos, sino que por sobre esto, en la extensión diacrónica constituida por generaciones sucesivas ella tiende a decrecer de un modo asintótico que a partir de algún momento se aproxima a cero.

La tercera crítica tiene un carácter inmanente y es el tiro de gracia al argumento de Rawls. De acuerdo a ésta, el argumento para incluir este principio está en contradicción con una premisa fundamental de la teoría. Aparte de suponer que los individuos en la PO no saben su edad y tampoco saben a qué generación pertenecen, Rawls supone que los individuos en la PO (a) son mutuamente desinteresados. Esta es, como vimos, una premisa central en la estructura contractual justificativa de Rawls. Sin embargo, para argumentar a favor del principio de ahorro, Rawls supone que los individuos en la PO (b) se preocupan por el destino de sus descendientes. Evidentemente estas dos premisas no se pueden congeniar. Si (b) es correcta, entonces (a) debe ser falsa, y viceversa. Dos comentarios son aquí necesarios:

En primer lugar, si fuese el caso que (b) es correcta, entonces ipor qué sólo suponer que los individuos tienen interés en sus descendientes inmediatos, y no en sus amigos, sus mascotas etc.? Evidentemente los individuos en la PO pueden saber que probablemente ellos tendrán personas por cuyo bienestar se preocuparán fuera de la PO. (Por lo mismo no es necesario, como Rawls afirma, que "lo esencial" en este argumento es que cada persona en la PO "se preocupará" por el bienestar de algunos de los individuos del futuro (RAWLS, 1971, 128-129) - esta es una premisa innecesariamente fuerte). Pero de esta información no se sigue que los individuos en la PO escogerán un principio que considere el bienestar de los individuos por cuyo bienestar ellos eventualmente se preocuparán, como no se sigue del conocimiento que eventualmente fuera de la PO nos preocuparemos por el bienestar de una mascota un principio de justicia que la considere. Lo que se sigue de este conocimiento, es que los individuos estarían interesados en poder perseguir este interés una vez fuera de la PO y para esto tratarían de asegurarse tantos bienes básicos como fuese posible mediante la elección de principios. En segundo lugar, y más importante, renunciar a (a) implicaría renunciar a la estructura argumentativa de Rawls. Desinterés es desinterés, y si 
(a) es válida, entonces no es posible justificar el principio de ahorro con esta argumentación.

2. Rawls admite en Political Liberalism que esta contradicción es real (RAWLS, 1993, 274 nota), y reacciona a esta crítica con su segundo argumento a favor del principio de ahorro. Rawls rechaza la premisa de buena voluntad. El peso argumentativo a favor de este principio debe remitirse al hecho que los individuos en la PO están interesados en sí mismos y son mutuamente desinteresados. Así rediseña la PO de tal modo, que los socios contratantes acordarían un principio de ahorro bajo la condición que "ellos deben querer que todas las generaciones previas lo hayan seguido" (RAWLS, 1993, 274). Este argumento debería funcionar independientemente de si efectivamente se tiene una cierta preocupación por los descendientes inmediatos. El interés propio los llevaría a escoger el principio de ahorro, porque éste aseguraría un punto de partida fuera de la $\mathrm{PO}$ en el que se dispondría de una cierta cantidad de bienes básicos (como ingresos y riquezas) que de otro modo no estaría asegurado. ${ }^{25}$ Lo que este argumento subraya es un hecho evidente: el bienestar de cada generación no depende sólo de lo que los miembros de cada generación hacen u omiten, sino que de lo que otros individuos, que ya no existen, hicieron u omitieron. De acuerdo a Rawls, este principio tiene que ser articulado de tal modo, que (a) pueda ser aceptado por todas las generaciones, independientemente de si las circunstancias económicas son difíciles, y (b) debe ser suficientemente flexible para garantizar que ninguna generación estará peor en relación a cualquier generación precedente.

Para la plausibilidad de este argumento es fundamental el que Rawls no supone que las generaciones se suceden una después de otra, sino que acepta la contemporaneidad de generaciones próximas. La sociedad es "un sistema de cooperación entre generaciones en el tiempo" (RAWLS, 1993, 274). De este modo, no se trata sólo de instituir un sistema de transferencias de una generación a otra, sino que de asegurar esta empresa de cooperación en razón del interés racional propio de cada individuo. Si bien en razón del argumento esbozado los individuos aceptarían el principio de ahorro, al entrar al sistema de cooperación cada generación tendría ciertamente la posibilidad de no cumplir los principios ya aceptados. Evidentemente, esto sería injusto. Esto se

${ }^{25}$ A modo de ilustración: así como cualquier individuo querría haber recibido de sus abuelos una herencia que le asegurase cierta holgura económica al comienzo de su vida adulta, todos los individuos estarían de acuerdo en considerar a sus descendientes en su herencia (WISSENBURG, 1998, cap. 5). 
debe a que, siguiendo la estructura argumentativa de Rawls, lo que es racional de ser escogido en la $\mathrm{PO}$, es justo fuera de ésta. Rawls trata de asegurarse contra la posibilidad de defección, en tanto supone que una de las dos capacidades que definen a las personas que pueden ser sujetos de justicia es el sentido de la justicia: un deseo por actuar de acuerdo a los principios de justicia. Por encima de esto, en el caso del principio de ahorro las generaciones tendrían una motivación racional extra para implementarlo: si de acuerdo al principio de ahorro una generación determinada recibe de la generación precedente una cierta cantidad de bienes básicos, pero en su momento se niega a hacer efectivo este principio en relación a la generación siguiente, ella destruiría la base de confianza en que se basa la empresa cooperativa, y ya que parcialmente las generaciones se traslapan, la generación que no hace efectivo el principio de ahorro tendría buenas razones para temer que el costo de su defección supere a sus ventajas. Aunque este argumento de Ravls es más plausible que el primero, no es conclusivo para justificar la inclusión del principio de ahorro:

Primero: si bien en la PO no hay generaciones primeras (de igual modo a como no hay individuos desfavorecidos), en la vida real si las hay. Pero la primera generación sólo puede perder al aceptar un principio de ahorro: ellos ahorran para la generación siguiente, sin haber recibido ningún beneficio de la generación precedente. En la PO sería racional suponer que podemos pertenecer a la primera generación que - porque las circunstancias lo permiten - puede tornar efectivos los principios de justicia. Todavía más: si es válida la argumentación de Rawls, quien rechaza el criterio de razón insuficiente (y así rechaza la posibilidad de establecer probabilidades para ocupar una posición social) como guía en una decisión bajo incertidumbre - como en la PO -, y favorece un criterio pesimista como el criterio Maximin, deberíamos suponer que pertenecemos a los más desfavorecidos y, de este modo, a la primera generación que implementará los principios de justicia. Como mencioné en el punto (a), Rawls tiene la pretensión que el principio de ahorro debe ser especificado de tal modo que pueda ser escogido por cualquier generación. Pero es difícil imaginarse por qué los individuos en la PO escogerían un principio de ahorro si suponen que pertenecen a la primera generación. Los individuos no escogerían un principio de ahorro entre generaciones sin, simultáneamente, querer protegerse ante la eventualidad de pertenecer a la primera generación. Pero yo no me imagino cómo podría ser establecido institucionalmente este modo de protección.

Una posibilidad podría ser establecer una cuota creciente de ahorro. De este modo, el principio de ahorro exigiría muy poco de una primera 
generación, de la segunda algo más de lo que recibió, etc. Pero esto no es una respuesta a la crítica expuesta: si la primera generación es la generación peor situada, cualquier principio de ahorro, también uno con una cuota mínimo, situará a esta generación en una situación peor que aquella en la que estaría sin este principio (y en el caso de un principio con una cuota creciente de ahorro, situaría a cualquier generación en una situación peor que sin este principio). Una segunda posibilidad sería establecer no sólo un principio de ahorro para las GGFF, sino que un principio de trueque que, como parte de un contrato intergeneracional, favorezca tanto a las GGFF inmediatas como a la generación precedente. ${ }^{26}$ De este modo, sería posible establecer un principio que no sólo nos obligase a ahorrar para las GGFF lo que querríamos que la generación pasada hubiese ahorrado para nosotros, como propone Rawls, sino que también obligase a las GGFF a pagar en retorno a la generación precedente una parte de lo que recibieron de ésta. Problemático es que si el ahorro implicase una cantidad positiva, el retorno sería siempre menor de lo que la generación pasada ahorró, y de este modo, el resultado de este principio sería siempre peor para la generación precedente que el resultado al rechazar un principio de ahorro. La elección de un principio como el señalado sólo tendría algún tipo de plausibilidad, si suponemos que las inversiones posibilitadas por la transferencia de recursos a la siguiente generación producirían un capital siempre mayor. Quizás este es el caso bajo el supuesto de una economía en una buena fase, o dicho de otro modo: un principio de "buen tiempo". Pero esta suposición no encuentra necesariamente un correlato empírico. Y ya que Rawls afirma que el principio de ahorro debería ser aceptable independientemente de la situación económica (punto b), no parece ser posible argumentar a favor de la aceptabilidad de este principio, tampoco con la extensión intergeneracional que he propuesto. Ciertamente, las conclusiones serían diferentes si suponemos que la empresa cooperativa llamada sociedad no tiene comienzo temporal. Pero esta última suposición está tan lejos de ser una ficción razonable, esto es, una ficción que no se aleje en un modo tan considerable de nuestra realidad empírica que los principios así justificados pierdan cualquier plausibilidad, que sería difícilmente aceptable en el diseño de un estado de naturaleza.

${ }^{26}$ Un principio de justicia intergeneracional similar al mencionado es defendido por Höffe (1993, capítulo 11). De acuerdo a su argumentación, que se retrotrae a la idea de justicia como trueque (Gerechtigkeit als Tausch), las diferentes etapas de la vida hacen razonable establecer un principio de acuerdo al cual las generaciones en edad productiva se hacen cargo del bienestar de los niños que, a su vez, cuando lleguen a formar generaciones en edad productiva se harán cargo no sólo del bienestar de los niños de la próxima generación, sino también del bienestar de la generación precedente que se hizo cargo de ellos en la niñez. 
Segundo: aunque fuese posible justificarlo, este principio no puede dar cuenta de obligaciones hacia generaciones distantes, sino sólo hacia aquellas que nos suceden. Esta crítica no se aplica sólo al principio de Rawls. Como hemos examinado, en general se aplica a cualquier argumento que pretenda derivar obligaciones hacia GGFF exclusivamente de obligaciones hacia descendientes inmediatos: si bien podemos tener obligaciones hacia nuestros descendientes porque somos causantes de su existencia, esto no implica que tengamos obligaciones hacia los descendientes de nuestros descendientes - el portador de esta última obligación tiene que ser la generación que los creó (compare NARVESON, 1978, 58). El complejo sistema de ahorros e inversiones necesarios para proteger los intereses de las GGFF no se puede retrotraer a cadenas de generaciones sucesivas que sólo son responsables por la generación siguiente (BARRY, 1977).

\subsection{2 ¿Extendiendo la posición original?}

¿Sería posible interpretar la teoría de Rawls de modo tal, que las GGFF, con sus preferencias y necesidades, sean incluidas en la CM? En mi opinión, aunque es posible reinterpretar la estructura argumentativa de Rawls en este sentido, las consecuencias se diferencian de un modo considerable de las que él sostiene en su teoría. A continuación argumentaré en este sentido:

Rawls pretende regular mediante principios de justicia contingencias moralmente arbitrarias. Pero aquellas a las que él refiere no cubren todas las que una teoría liberal interesada en garantizar igualdad de oportunidades debiera considerar. El caso de la pertenencia generacional es claro. Mi pertenencia a ésta generación es moralmente contingente de un modo similar a mis dotes innatos y posición económica y social inicial: no puedo realizar nada contra ésta (y, p.ej., hacerme congelar para despertar en doscientos años en una generación particular bien conocida), ni por ésta (por más que me esfuerce no podré ser un noble en la Venecia del siglo XV). Esta contingencia tiene consecuencias importantes en relación a las oportunidades relevantes disponibles. ${ }^{27} \mathrm{Y}$ en buena medida las oportunidades disponibles se pueden retrotraer a las acciones y omisiones de las generaciones anteriores. Para regular algunos de los resultados que se dejan retrotraer a esta contingencia moralmente arbitraria requeriríamos reformular la PO limitando el conocimiento

${ }^{27}$ Un problema quizás insoluble en la ejecución de este experimento mental refiere a la (in)conmensurabilidad entre las oportunidades relevantes en las distintas épocas en las que las generaciones desarrollan su vida. En este texto no me referiré a este problema. 
disponible relativo a nuestra pertenencia generacional. En la PO deberían estar presentes los representantes de todas las generaciones, o - una segunda posibilidad - los individuos no deberían saber a qué generación particular pertenecen ellos y todos aquellos con los que deben realizar un contrato. Rawls afirma que la sociedad es una empresa cooperativa a través del tiempo. De este modo, los individuos en la PO no estarían sólo motivados en definir principios de justicia para regular la interacción social dentro de una sociedad organizada estatalmente, sino que también en definir principios que regulen la interacción entre las generaciones y beneficien a la generación en la que vivirán - sin saber cuál es ésta. Evidentemente, el principio de ahorro propuesto por Rawls es un principio de este tipo. Pero como examinamos, es un principio insuficiente. Mejor que este principio sería uno que considerase a todas las generaciones que nos sucedan como receptoras de nuestras obligaciones o como portadoras de derechos hacia nosotros. ${ }^{28}$

Sin embargo, esta extensión no es compatible con elementos centrales de la teoría. Un problema refiere a la eventualidad examinada: podríamos pertenecer a la primera generación que no está motivada por establecer principios intergeneracionales. Una estrategia de solución implicaría cuestionar el rechazo (por cierto, apenas argumentado) de Rawls de un criterio menos pesimista como guía en una decisión bajo incertidumbre. Si aceptásemos un criterio para decidir de acuerdo a las probabilidades de pertenecer a una generación particular (el criterio de razón insuficiente), entonces los individuos en la PO decidirían bajo el conocimiento de que la probabilidad de pertenecer a la primera generación es mínima en relación a la probabilidad de pertenecer a alguna de las otras generaciones que se beneficiarían de un principio de ahorro. De este modo, ellos estaría dispuestos a asumir el riesgo (por lo demás limitado: un principio de ahorro no se puede equiparar a un principio que, p. ej., permite la esclavitud) de aceptar un principio de ahorro que probablemente los favorecerá.

Sin embargo, este cambio en la argumentación de Rawls no estaría exento de repercusiones profundas en la teoría. Si es razonable - como en mi opinión lo es - utilizar un criterio que permita evaluar probabilidades para decidir en la $\mathrm{PO}$, entonces los individuos también deberían emplear este criterio para decidir qué principios de justicia ellos escogerían para regular las interacciones dentro de una sociedad organizada. Y los resultados de la aplicación de este criterio no corresponden a los principios de justicia que caracterizan esta teoría, sino más bien, como

28 Un principio que en mi opinión podría corresponder a esta exigencia, es el "restraint principle" defendido por Wissenburg (1998, cap. 5). 
ha sido famosamente discutido, al principio de utilidad media (si tengo la misma probabilidad que cualquier otro de ocupar cualquier posición social, sería racional escoger principios que maximicen el promedio de utilidad). ${ }^{29}$ De este modo, argumentar a favor de un principio de ahorro con el aparataje argumentativo de Rawls llevaría a modificar elementos centrales de su teoría.

\section{Imparcialidad y la extensión diacrónica de la comunidad moral}

La alternativa contractual a teorías que recurren al interés propio son teorías que se basan en la imparcialidad. ${ }^{30}$ ¿Es posible incluir a las GGFF en la CM dentro de estos marcos argumentativos? En mi opinión, es posible. Sin embargo, la teoría resultante se diferencia en aspectos importantes de los entendimientos contractuales usuales.

De acuerdo a una teoría contractual que se basa en la imparcialidad la respuesta a la pregunta: "¿por qué debo asentir a la relación contractual?", no es, primeramente, una apelación a la promoción de los intereses propios, sino que una apelación a nuestro interés moral en establecer una relación moral justificable con y hacia los otros. La igualdad, que las teorías contractuales que se basan en el interés propio caracterizan como igualdad natural en relación a la vulnerabilidad y a la capacidad de poder, es entendida por estas teorías como una igualdad moral que debe ser considerada: podemos promover nuestros intereses, bajo la condición de que en este proceso reconozcamos a los otros como sujetos morales relevantes y los respetemos en forma correspondiente. Así, la participación en el contrato no está mediada por el potencial de amenaza, sino que por esta igualdad moral que debe ser respetada. Pero estas teorías no proporcionan ninguna justificación de esta igualdad. Lo que ellas ofrecen es una aclaración de lo que esta igualdad fundamental debe implicar. De este modo, ellas cargan un equipaje moral más pesado que las teorías discutidas. A continuación argumentaré, de un modo esquemático, a favor de la inclusión de las GGFF en este marco conceptual.

En sus diversas interpretaciones, la imparcialidad implica que debemos una justificación a todos aquellos que son afectados negativamente en

${ }^{29}$ Las discusiones con respecto a la utilización del criterio Maximin, como Rawls propone, en el contexto de la teoría de la decisión racional para elaborar la respuesta en la $\mathrm{PO}$, son antiguas y conocidas, pero no por esto menos atingentes. Esta crítica fue elaborada ya temprano por Harsanyi (1975).

30 Ejemplos de teorías contractuales de carácter político y moral que se basan en la imparcialidad son las articuladas por Barry $(1989,1995)$ y Scanlon (1998) respectivamente. 
razón de nuestro accionar, y una justificación tal, que ellos - como sujetos morales relevantes - puedan razonablemente aceptar (compare SCANLON, 1998). La justificación debida puede tomar la forma de un consentimiento general. De acuerdo a Kant, p. ej., una norma moral es justificada, cuando cada cual la puede querer como una ley general. Pero: ¿tenemos buenos argumentos para limitar la clase de todos aquellos a los que debemos una justificación exclusivamente a los seres humanos actualmente existentes? En mi opinión, si asumimos la imparcialidad como punto de partida argumentativo, no hay modo de justificar esta limitación. Si somos responsables por las consecuencias de nuestras acciones, lo somos también cuando nuestras acciones perjudican a individuos del futuro.

Imparcialidad con respecto a las GGFF implicaría considerar qué razones podemos esperar que puedan aceptar como justificadoras de aquellas de nuestras acciones que las perjudiquen. Con palabras kantianas - y estas teorías son a menudo denominadas teorías de inspiración kantiana (compare KYMLICKA, 1991) - esto significaría no tratar a las GGFF simplemente como medio, sino que siempre simultáneamente como fin. Por cierto, no es necesario que los miembros de las GGFF existan actualmente (lo que evidentemente es un oxímoron) para que esta articulación de razones tenga sentido. De un modo contrafáctico es posible preguntar, qué razones aceptarían las GGFF. Como mencioné al comienzo de este artículo, universalización pertenece a la moral de un modo constitutivo. Si estas razones no son aceptables de un modo contrafáctico, entonces las decisiones son moralmente reprochables. En esta línea de argumentación sería posible argüir que el concepto de "humanidad" incluye no sólo aquellos seres humanos actualmente existentes, sino también los seres humanos del futuro. Una acción moralmente correcta, como acción que refiere a la humanidad en cuanto tal, debe considerar a las GGFF. De este modo, y contra lo que proponen numerosos autores (p. ej. HANS JONAS, 1979), no requerimos de ningún criterio nuevo para juzgar las acciones que afectarán a las GGFF. Solamente los contenidos a los que se relacionan las acciones son más amplios: hacer algo que perjudique a aquellos que vivirán después de nosotros de un modo que no podemos razonablemente esperar que ellos puedan aceptar, es moralmente reprochable.

\section{1 ¿Cuáles generaciones?}

¿A cuáles GGFF les debemos razones por nuestras acciones? La primera posibilidad es sostener la tesis que debemos una justificación a todos los seres humanos que existen y que efectivamente existirán. La segunda posibilidad es que se la debemos tanto a los seres humanos que existen actualmente, como a todos aquellos que pueden existir en el futuro. 
Como discutí al comienzo de este artículo, las GGFF pueden ser receptoras de nuestras obligaciones o pueden ser portadoras de derechos, bajo la condición de su existencia. Correspondientemente, parece ser que la respuesta correcta es que debemos razones a todos aquellos seres humanos vivos y que efectivamente vivirán, y no a todos aquellos que podrían vivir. Sin embargo, esta respuesta es problemática. ${ }^{31}$ Las dificultades se retrotraen a una variante del "problema de la noidentidad", de acuerdo a la cual no tendríamos obligaciones hacia las GGFF (PARFIT, 1983). Este argumento lo podemos ilustrar con el siguiente caso (compare PARFIT, 1976; otra variante se encuentra en PARFIT, 1984, 367):

Mujer A desea quedar embarazada. El médico le da dos informaciones. En primer lugar, le indica que ella tendrá un niño con malformaciones congénitas que le harán llevar una vida difícil, pero en todo caso por sobre el mínimo como para considerarla vivible (es decir, para preferir vivir por sobre morir). En segundo lugar, le indica que si esperase tres meses antes del embarazo, estas malformaciones serían evitadas. Mujer A no espera los tres meses. Como consecuencia tiene un niño con malformaciones. ¿Cómo podemos evaluar su acción? Cuando en el futuro el niño increpe a su madre por no haber esperado los tres meses, ella tendría un argumento irrebatible: "si hubiese esperado los tres meses tu no habrías nacido. Por lo tanto, no tienes ninguna razón para presentar reclamaciones legítimas".

Este argumento apunta a una paradoja en relación a los individuos futuros: cada individuo está caracterizado de acuerdo a sus condiciones de surgimiento únicas. Por lo tanto, un individuo no puede reclamar para sí mejores condiciones de vida, porque bajo estas condiciones no habría sido él, sino que otro, el que habría entrado en la vida. Porque las condiciones ya dadas son las únicas posibles, ellas son las mejores. Ya que correspondientemente ningún miembro de las GGFF podría reclamar que preferiría haber nacido bajo otras condiciones (porque en ese caso, no él, sino que otro individuo habría nacido), no tendríamos obligaciones hacia GGFF. En este caso, decisiones actuales que afecten las condiciones de gestación de las GGFF estarían siempre justificadas.

Si consideramos que $\mathrm{A}$ ha hecho algo moralmente reprobable, o que una generación no ha considerado apropiadamente el bienestar

31 Estas dificultades afectan mayormente a las teorías utilitarias, para las que resulta central definir cuáles generaciones deben ser consideradas en la realización de los diferentes cálculos agregativos de utilidades. Pero las teorías contractuales tampoco están exentas de estas dificultades. Como señalé al comienzo, en este texto no me referiré a las teorías utilitaristas. 
de las generaciones futuras que ha creado, entonces tenemos que asumir que la clase de individuos que deben ser considerados cuando tomamos nuestras decisiones de acción, no se define en relación a todos los individuos que efectivamente vayan a existir (como en el ejemplo mencionado), sino que en relación a todos aquellos individuos que pueden existir. Si el bienestar de los individuos posibles (aquellos que existirían bajo otras condiciones de surgimiento) debe ser considerado, entonces podríamos considerar críticamente acciones que generen condiciones de gestación que están lejos de ser óptimas.

Sin embargo, asumir esta tesis implica problemas serios. Un problema general e intratable que surge al considerar a los individuos posibles refiere al estatus metafísico de las generaciones posibles. Otra consecuencia poco deseable de esta tesis en un marco teórico utilitarista - dejando de lado los problemas de indexicabilidad que trae consigo un conjunto ilimitado - es que no podemos evitar un cierto tipo de ingeniería social, en ocasiones difícilmente defendible: bajo determinadas circunstancias podemos estar bajo la obligación de crear nuevas generaciones. ${ }^{32}$ P. ej., siguiendo a Hare, quien como defensor del así llamado Utilitarismo de Preferencias acepta esta respuesta, la pregunta central con respecto a las GGFF refiere a la cantidad óptima de individuos (humanos y no-humanos) que deben existir para alcanzar un cálculo óptimo de utilidades considerando los límites medioambientales (HARE, 1993a). Por sobre esto, este modo de argumentar conlleva conclusiones difíciles de aceptar. Una de éstas, que ha sido intensamente discutida, es la así llamada "conclusión repugnante" a la que están sujetos ciertos tipos de utilitarismo. ${ }^{33}$ De acuerdo a esta conclusión, para alcanzar el óptimo en el proceso agregativo habría que aumentar la cantidad de individuos hasta el punto en que su calidad de vida individual descienda al límite necesario para considerar la vida como vivible.

En mi opinión, el argumento basado en el problema de la no-identidad es lógicamente correcto. ${ }^{34}$ Sin embargo, los límites de esta argumentación son más estrechos que lo que a primera vista parece:

Primero: no todas las acciones presentes que perjudican a las GGFF definen sus condiciones de gestación - de hecho, la mayoría de las acciones que son cuestionadas cuando se argumenta a favor de obligaciones hacia

32 Para una discusión de esta tesis en un marco argumentativo utilitarista compare Singer (1993, cap. 5), y Hare (1993b).

33 Numerosas discusiones de esta conclusión se encuentran entre los artículos compilados en Sikora/Barry (1978).

34 Como consecuencia de sus reflexiones acerca del problema de la identidad, Parfit argumenta a favor de inconsecuencia en el caso de las GGFF. 
las GGFF no son de este tipo. ${ }^{35}$ Este punto es simple y lo podemos ilustrar con un caso hipotético - pero que no se diferencia en forma relevante del modo en que muchas generaciones, también la nuestra, han actuado y actúan: si una generación actual, para mantener o mejorar su alta calidad de vida, consumiese todos los recursos naturales disponibles sin proveer alternativas, las condiciones de vida de las próximas generaciones serían miserables. Si tuviésemos que justificar este accionar frente a ellas, difícilmente podríamos indicar que si hubiésemos actuado de otro modo ellas no habrían existido, y que, por lo tanto, ellas no tienen ninguna reclamación legítima. ${ }^{36} \mathrm{Si}$ nuestra generación hubiese renunciado al derroche de recursos naturales y hubiese realizado inversiones a futuro, la siguiente generación no habría dejado de existir y sus miembros tampoco habrían sido substituidos por otros (como en el ejemplo mencionado). Lo mismo es válido en caso en que, p. ej., la destrucción del medioambiente que produce la generación actual disminuyese de un modo drástico la posibilidad de las GGFF para desarrollar una vida relativamente sana. En los casos mencionados, las GGFF habrían existido con una calidad de vida mejor, si, p. ej., la generación actual hubiese puesto en cuestión su "derecho" ilimitado a conducir ocho cilindros o a permanente aire acondicionado. Universalización - situarse en la posición del otro, p. ej. la de los individuos futuros - pertenece a la moral en forma constitutiva. ${ }^{37}$

35 Ciertamente hay casos en los que es difícil encontrar alguna guía teórica. Imagine que en su gran mayoría las generaciones actuales se abstuviesen de crear los individuos que constituirán las GGFF. En este caso, la descendencia sería tan reducida que, debido a los procesos de cooperación necesarios para generar sociedades relativamente afluentes, se tornaría imposible desarrollar una vida con una calidad que se eleve de un modo relevante por sobre el mínimo necesario para considerar que la vida es vivible. En este caso, las nuevas generaciones podrían tener un reclamo justificado frente a las generaciones actuales por no haber generado la cantidad necesaria de nuevos individuos para mantener una calidad de vida aceptable. En todo caso, este no es un reclamo realizado desde la perspectiva de los miembros no-existentes de la GF.

36 A favor de esta conclusión se puede mencionar que un alto índice de calidad de vida no va usualmente acompañado por una tasa de crecimiento poblacional mayor.

37 Aunque puede ser que no es posible tener acceso a cómo es para un determinado sujeto perteneciente a una GF el tener una sensación (dicho de otro modo utilizando la famosa fórmula de Nagel (1981): si el así llamado problema de "what it is likeness" es insuperable), y que, por lo tanto, no tenemos posibilidad de acceder a sus Qualia, esto no constituiría una objeción al proceso de universalización en la moral. En este proceso, la información relevante no es "what it is likeness", sino que-oraciones. Es decir, no es relevante tener acceso a cómo un individuo particular experimenta una situación desde adentro (p. ej., una vida individual y social con recursos extremadamente limitados, o con agua escasa y contaminada, etc.), sino saber que se está en esa situación. Aquí hay ciertamente límites. Pero éstos dependen de nuestros conocimientos empíricos y no de nuestra posibilidad de tener acceso a los Qualia de otro ser. Y en los casos en que el medioambiente es considerado como un recurso para las GGFF, estos conocimientos están 
Segundo: hay al menos un caso en que las acciones presentes definen las condiciones de surgimiento de las GGFF del modo existencial requerido por el argumento. En este caso una generación produciría una descendencia tan numerosa, que, considerando los recursos disponibles, para las GGFF se tornaría imposible llevar una vida con una calidad que se eleve de un modo relevante por sobre el mínimo necesario para considerar que la vida es vivible. Ante la reclamación de las GGFF por no haber establecido sistemas para limitar la reproducción humana, se podría dar el tiro de gracia argumental ya mencionado: "si hubiésemos limitado la reproducción muchos de ustedes no existirían. La vida que ustedes llevan, si bien bajo numerosos aspectos es miserable, no lo es hasta el punto de tornar la vida insuficientemente valiosa como para preferirla por sobre la no-existencia. Por lo tanto, no hay ninguna razón para presentar reclamaciones". Si no queremos aceptar la tesis que somos responsables frente a todas las generaciones posibles - y, como examiné, hay buenas razones para rechazar esta tesis - este argumento es, en mi opinión, irrebatible.

Sin embargo, si aceptamos una interpretación particular de la reclamación de las GGFF, este argumento puede ser hasta un cierto punto cualificado. De acuerdo a esta interpretación, las GGFF no reclaman frente a las generaciones presentes que éstas no limitaron la reproducción de la especie, de modo tal que la vida de ellos pudiese haber alcanzado una mayor calidad. La reclamación fundamental es que las generaciones pasadas no hicieron nada para evitar que la calidad de su vida en cuanto GGFF fuese medrada de tal modo. La diferencia entre estas dos interpretaciones es importante. En esta interpretación no es relevante la sobrepoblación en cuanto tal, sino que la calidad de vida que esta conlleva. En mi opinión, esta interpretación corresponde de un modo más apropiado al objeto de la reclamación de las GGFF. De acuerdo a esta reclamación, la generación actual puede determinar la tasa de crecimiento poblacional como considere apropiado. Crucial es que la generación actual realice algo para que la calidad de vida de las GGFF no descienda del modo señalado. P. ej., las generaciones actuales podrían bajar su calidad de vida, y así ahorrar recursos naturales y realizar inversiones a futuro, o ellas podrían inventar nuevos modos de

disponibles. La situación no es diferente de un modo relevante del caso de la justicia distributiva. P. ej., para afirmar que la falta de oportunidades (o de bienes básicos, o de capacidades centrales, etc.) de un individuo con una minusvalía debe ser compensada con recursos extras, no es necesario que tengamos acceso a sus estados mentales. En este caso es suficiente que tengamos conocimiento de lo que implica esta minusvalía (movilidad reducida, etc.), para establecer que una teoría que aspire a igualar las oportunidades tiene un caso para justificar algún tipo de compensación. 
generación de energía, o colonizar nuevos planetas, etc. En el caso de esta interpretación de la reclamación de las GGFF, las generaciones actuales sólo podrían responder con el tiro de gracia argumental ya señalado cuando, sin considerar la disminución de la tasa de crecimiento poblacional, no hubiese habido ninguna posibilidad disponible para mejorar las condiciones de vida de las GGFF.

\section{Consideraciones finales}

En este texto he mostrado que no es lógicamente inconsistente sostener obligaciones hacia las GGFF o que éstas son portadoras de derechos. En segundo lugar he examinado las posibilidades que ofrece un marco teórico contractual para incluir a las GGFF en la CM y así justificar estas obligaciones o derechos. Teorías contractuales que basan su justificación en el interés propio como premisa única o como una de sus premisas básicas no pueden incluir a las GGFF en la CM. La diferencia de poder que se retrotrae a la posición temporal hace esta inclusión imposible. Y las estrategias para establecer obligaciones indirectas hacia GGFF están sujetas a límites estrechos que tornan estas teorías poco atractivas. Por el contrario, teorías contractuales que se basan en la imparcialidad pueden realizar esta inclusión. De este modo, dentro de estos marcos conceptuales es posible justificar tanto obligaciones hacia éstas como sus derechos. La consideración moral de las GGFF y las limitaciones en nuestras acciones que se derivan de ésta, se retrotraen al empleo de criterios morales corrientes. Sin embargo, nada de lo indicado en este texto nos indica cuáles son las obligaciones que les debemos a las GGFF o cuáles son sus derechos. La determinación de éstos implicaría, entre otras cosas, encontrar una respuesta al problema de la substracción del valor del futuro. En mi opinión, estas obligaciones o derechos no se diferencian fundamentalmente de todos aquellos que debemos u otorgamos a los individuos actualmente existentes (cuando éstos se pueden aplicar considerando la diferencia temporal). Pero en este texto no he argumentado en este sentido.

\section{Referencias}

BARRY, Brian. "Justice between generations". In: HACKER, P. M. S.; RAZ, J. (Eds.). Law, Morality and Society. Essays in honor of H. L. A. Hart. Oxford, 1977.

BARRY, Brian. Justice as Impartiality. Oxford University Press, 1995.

BARRY, Brian. Theories of Justice. University of California Press, 1989.

BIERI, Peter. Analytische Philosophy des Geistes. 3. ed. Königstein/Ts., 1981.

BIRNBACHER, Dieter. Verantwortung für zukünftige Generationen. Stuttgart: Reclam, 1988. 
BIRNBACHER, Dieter (Ed.). Ökologie und Ethik. Stuttgart: Reclam, 1980.

DAVIDSON, Donald. "Rational Animals". In: LEPORE, E.; MCLAUGHLIN, B. (Eds.). Actions and Events: Perspectives on the Philosophy of Donald Davidson. Oxford: Basil Blackwell 1985.

FEINBERG, Joel. "Die Rechte der Tiere und zukünftiger Generationen". In: BIRNBACHER, D. (Ed.). Ökologie und Ethik. Stuttgart: Reclam, 1980.

FRANKFURT, Harry. "Equality and Respect". In: Social Research, 64, 1 (1997).

FRENCH, Peter. Collective and Corporate Responsibility. New York: Columbia University Press 1984.

FREY, Raymond G. "Rights, Interests, Desires and Beliefs", American Philosophical Quarterly, 16 (1979).

GAUTHIER, David. Moral by Agreement. Oxford: Oxford University Press, 1986.

GOLDING, Martin. "Obligations to Future Generation". In: PATRIDGE, E. (Ed.). Responsibilities to Future Generations: Environmental Ethics. New York: Prometheus Books, 1981.

GOROVITZ, S. (Eds.). Moral Problems in Medicine. New York: Englewood Cliffs, 1976. GOSEPATH, Stefan. Gleiche Gerechtigkeit. Frankfurt am Main: Suhrkamp, 2004.

HACKER, P. M. S.; RAZ, Joseph (Eds.). Law, Morality and Society. Essays in honor of H. L. A. Hart (Oxford, 1977).

HARE, R. M. (1993a). "Why I am only a Demi-Vegetarian". In: HARE, R. M. Essays on Bioethics (Oxford: Oxford University Press, 1993).

HARE, R. M. (1993b). "Possible People". In: HARE, R. M. Essays on Bioethics. Oxford: Oxford University Press, 1993.

HARSANYI, John. "Can the Maximin Principle Serve as the Basis for Morality? A Critique of John Rawls's Theory”, American Political Science Review, 69 (1975).

HÖFFE, Otfried. Moral als Preis der Moderne. Frankfurt am Main: Suhrkamp, 1993.

JONAS, Hans. Das Prinzip Verantwortung. Versuch einer Ethik für die technologische Zivilisation. Frankfurt am Main: Insel Verlag, 1979.

KANT, Immanuel. Gesammelte Schrifften. Königlich-Preußische Akademie der Wissenschaften Berlin (AA) - Idee zu einer allgemeinen Geschichte in weltbürgerlicher Absicht.

KREBS, Angelika (Ed.). Naturethik. Frankfurt am Main: Suhrkamp, 1997.

KREBS, Angelika (Ed.). Gleichheit oder Gerechtigkeit. Frankfurt am Main: Suhrkamp, 2000.

KYMLICKA. "The social contract tradition". In: SINGER, P. (Ed.). A Companion of Ethics. Blackwell, 1991.

LEPORE, E.; McLAUGHLIN, B. (Eds.). Actions and Events: Perspectives on the Philosophy of Donald Davidson. Oxford: Basil Blackwell. 1985.

LOCKE, John. The Second Treatise of Government. LASLETT, P. (Ed.). Cambridge: Cambridge University Press, 1960.

LOEWE, Daniel. "Inclusión de animales no-humanos en un marco de argumentación teórico contractual”. In: Veritas, Porto Alegre, Marzo, 2008. 
MACKIE, John Leslie. Ethik. Auf der Suche nach dem Richtigen und Falschen. Stuttgart, 1981.

MACLEAN, Douglas; BROWN, Peter G. Energy and the Future. New York: Rowman and Littlefield, 1983.

MAY, Larry. The Morality of Groups: Collective Responsibility, Group-Based Harm and Corporate Rights. Notre Dame, Indiana: University of Notre Dame Press, 1987.

MCMURRIN, S. M. (Ed.). Tanner Lectures on Human Values. Cambridge: Cambridge University Press, 1980.

NAGEL, Thomas. "Wie ist es, eine Fledermaus zu sein?". In: BIERI, P. (Ed.). Analytische Philosophy des Geistes. 3. ed. Königstein/Ts., 1981.

NARVESON, Jan. "Future people and us". In: SIKORA, R. I.; BARRY, B. (Eds.). Obligations to future generations. Philadelphia, 1978.

NOZICK, Robert. Anarchy, State, and Utopia. Oxford: Blackwell, 1974.

NUSSBAUM, Martha. Frontiers of Justice. Disability, Nationality, Species Membership (Harvard University Press, 2006).

PARFIT, Derek. "Rights, Interests and Possible People". In: GOROVITZ, S. (Ed.). Moral Problems in Medicine. New York: Englewood Cliffs, 1976.

PARFIT, Derek. "Energy Policy and the Further Future: The identity Problem". In: MACLEAN, D.; BROWN, P. G. Energy and the Future. New York: Rowman and Littlefield, 1983.

PARFIT, Derek. Reasons and Persons. Oxford, 1984.

PATRIDGE, Ernest (Ed.). Responsibilities to Future Generations: Environmental Ethics. New York: Prometheus Books, 1981.

PERLER \& WILD (Eds.). Der Geist der Tiere. Frankfurt am Main: Suhrkamp, 2005.

RAWLS, John. A Theory of Justice. Harvard University Press, 1971.

RAWLS, John. Political Liberalism. Columbia University Press, 1993.

RAZ, Joseph. The Morality of Freedom. Oxford Clarendon Press, 1986.

REGAN, Tom. The Case for Animals Rights. London, 1984.

SCANLON, Thomas. What We Owe to Each Other. Harvard University Press, 1998.

SCARANO, Nico; SUÁREZ, Mauricio (Eds.). Ernst Tugendhats Ethik. München: C. H. Beck, 2006.

SCHWEITZER, Albert. "Die Lehre von der Ehrfurcht vor dem Leben”. In: SCHWEITZER, A. Kultur und Ethik (1923). In: Gesammelte Werke in fünf Bänden, Band 2. München: C. H. Beck, 1974.

SEARLE, John. "Der Geist der Tiere". In: PERLER \& WILD (Eds.). Der Geist der Tiere. Frankfurt am Main: Suhrkamp, 2005.

SEN, Amartya. "Equality of What?". In: MCMURRIN, S. M. (Ed.). Tanner Lectures on Human Values. Cambridge: Cambridge University Press, 1980.

SIKORA, R. I.; BARRY, B. (Eds.). Obligations to future generations. Philadelphia, 1978.

SINGER, Peter (Ed.). A Companion of Ethics. Blackwell, 1991.

SINGER, Peter. Practical Ethics. 2. ed. Cambridge: Cambridge University Press, 1993. 
STEMMER, Peter. Handeln zugunsten anderer. De Gruyter, 2000.

SUNSTEIN \& NUSSBAUM (Eds.). Animal Rights. Current Debates and New Directions. Oxford: Oxford University Press, 2004.

TUGENDHAT, Ernst. "Erwiderungen". In: SCARANO, N.; SUÁREZ, M. (Eds.). Ernst Tugendhats Ethik. München: C. H. Beck, 2006, p. 273-312.

TUGENDHAT, Ernst. Vorlesungen über Ethik. Frankfurt am Main: Suhrkamp, 1993.

TUGENDHAT, Ernst. "Wer sind alle?". In: KREBS, A. (Ed.). Naturethik. Frankfurt am Main: Suhrkamp, 1997.

WISE, Steven. "Animal Rights, One Step at Time". In: SUNSTEIN \& NUSSBAUM (Eds.). Animal Rights. Current Debates and New Directions. Oxford: Oxford University Press, 2004.

WISSENBURG, Marcel. Green Liberalism. The free and the green society. Routledge, 1998. 